\title{
THE DEVELOPMENT AND \\ VERIFICATION OF A DESIGN GUIDE FOR LMFBR SODIUM PIPING
}

TECHNICAL REPORT 100

PREPARED FOR

U S ATOMIC ENERGY COMMISSION

CONTRACT NO AT(04-3)-781

BRAUN PROJECT 4122-W

UNITED NUCLEAR PROJECT 2351 


\section{DISCLAIMER}

This report was prepared as an account of work sponsored by an agency of the United States Government. Neither the United States Government nor any agency Thereof, nor any of their employees, makes any warranty, express or implied, or assumes any legal liability or responsibility for the accuracy, completeness, or usefulness of any information, apparatus, product, or process disclosed, or represents that its use would not infringe privately owned rights. Reference herein to any specific commercial product, process, or service by trade name, trademark, manufacturer, or otherwise does not necessarily constitute or imply its endorsement, recommendation, or favoring by the United States Government or any agency thereof. The views and opinions of authors expressed herein do not necessarily state or reflect those of the United States Government or any agency thereof. 


\section{DISCLAIMER}

Portions of this document may be illegible in electronic image products. Images are produced from the best available original document. 


\section{G F B R A U N $\quad$ \& $\quad \mathrm{G}$ O \\ Engineers}

ALHAMBRA CALIFORNIA 91802

$2 A n-781.100$

July 23, 1969

H B Fry, Contracting officer

Contract AT (04-3)-781

AEC San Francisco

2111 Bancroft Way

Berkeley, California $95704 \quad$ BAL-76

Dear Mr Fry

\begin{tabular}{l} 
PROGRAM PLAN ORIENTATION \\
TECHNICAL REPORT 100 \\
LMFBR PIPING DESIGN GUIDE \\
AEC SAN FRANCISCO \\
PROJECT $4122-W$ \\
\hline
\end{tabular}

Transmitted herewith are two copies of the final report covering a description of the purpose, scope, and work plan for developing the LMFBR Piping Design Guide.

The report was prepared for the benefit of interested parties unfamiliar with the technical details of the contract. We have incorporated review comments from the preliminary draft and added a section describing changes made to the work plan since the preliminary draft was issued for review.

Comments on the report will be welcome, and should further clarification be desired, requests should be directed to the project manager. Further revision of the report is not contemplated.

RFD IV

Sincerely yours

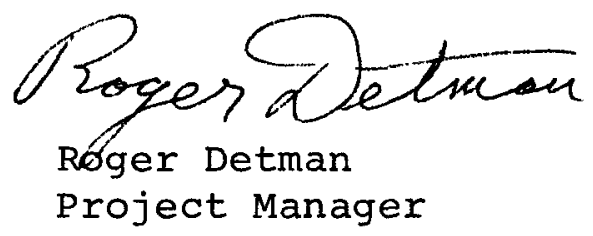




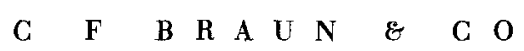

CC H B Fry, Contracting officer -original plus one Director, RDT, HQ

Asst. Director, Project Management, RDT, HQ Asst. Director, Plant Engineering, RDT, HQ Asst. Director, Engineering Standards, RDT, HQ Asst. Director, Reactor Engineering, RDT, HQ Asst. Director, Reactor Technology, RDT, HQ Chief, Liquid Metal Projects Br., RDT, HQ Project Manager, LMEC, RDT, HQ -2

Program Manager, LMFBR, RDT, HQ Chief, Facilities Br., RDT, HQ Chief, Components Br., RDT, HQ Chief, Instrumentation \& Control Br., RDT, HQ Chief, Liquid Metal System Br., RDT, HQ Project Manager, FFTF, RDT, HQ Manager, SAN-AEC Director, LMFBR Program office (ANL) RDT Senior Site Representative (AI) -2 Director, LMEC -3 Contract Representative, CP-AEC RDT Senior Site Representative (PNL) Project Administrator, FFTF Project office (RL) Manager, Sodium Components (PNL) Manager, FFTF Project (PNL)

J R Boldt, BNL, FFTF -2

A Amorosi, LMFBR Program office, ANL C Roderick, Westinghouse, FFTF Stewart $K$ Vandenberg, GE, San Jose $M$ W Croft, B\&W Co, 1000 MW Studies I E Glasgow, AI, 500 MW Dem. Plant R C Murphy, Crane Co B J Milleville, Rockwell Mfg Co G L Ryland, Aerojet-General 


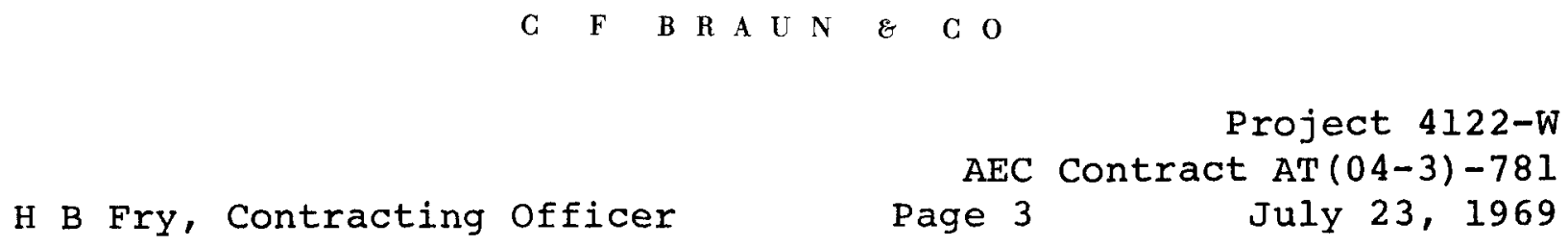




\title{
LEGAL NOTICE
}

This report was prepared as an account of work

sponsored by the United States Government. Neither

the United States nor the United States Atomic Energy

Commission, nor any of their employees, nor any of

their contractors, subcontractors, or their employees,

makes any warranty, express or implied, or assumes any

legal liability or responsibility for the accuracy, com-

pleteness or usefulness of any information, apparatus,

product or process disclosed, or represents that its use

would not infringe privately owned rights.

\section{THE DEVELOPMENT AND VERIFICATION OF}

\section{A DESIGN GUIDE FOR LMFBR SODIUM PIPING}

TECHNICAL REPORT

100

\author{
Prepared for US Atomic Energy Commission \\ Contract No AT $(04-3)-781$ \\ Braun Project 4122-W
}

United Nuclear Project 2351

C F BRAUN \& $\mathrm{CO}$
Alhambra
California

July 23, 1969 
PREFACE

In response to a Request for Proposal from New York Operations Office, US Atomic Energy Commission, for the development and verification of a Design Guide for LMFBR Sodium Piping systems, C F Braun \& Co, with United Nuclear Corporation as a principal subcontractor, submitted a detailed work plan for the proposed project. This work plan was subsequently adopted as the basis of a contract between USAEC and Braun, and work started on October 1, 1968.

With the passage of time the need has arisen for a convenient summarization of the Design Guide objectives and work plan, as a medium for orienting those who are unfamiliar with the overall scope of the task. This Technical Report has been prepared to serve that purpose.

It should be borne in mind that, as the development of the Design Guide progresses, some deviation from the original work plan may prove expedient, without compromise to the main objectives of the project. One such revision to the work plan was found advisable since the original draft of this document was prepared. The revised work plan is presented in section 12, which has been added to describe the mid-course changes made in the critical path schedule to offset the technical difficulties encountered and still meet the original target completion date.

C F Braun \& Co

Alhambra, California 
THE DEVELOPMENT AND VERIFICATION OF

A DESIGN GUIDE FOR LMFBR SODIUM PIPING

TECHNICAL REPORT 100

CONTENTS

$\underline{\text { PAGE }}$

1 INTRODUCTION

$1-1$

2 LMFBR PROGRAM PLAN

$2-1$

3 LMFBR SYSTEM REQUIREMENTS

$3-1$

4 LMFBR PIPING SYSTEMS

$4-1$

5 DESIGN GUIDE OBJECTIVES

$5-1$

6 GUIDE PREPARATION WORK PLAN

$6-1$

7 GUIDE VERIFICATION

$7-1$

8 REVIEW PROCEDURES

$8-1$

9 R\&D REQUIREMENTS

$9-1$

10 ORGANIZATION AND SCHEDULE

$10-1$

11 BIBLIOGRAPHY

$11-1$

12 WORK PLAN REVISION

$12-1$

APPENDIX A - LMFBR PROGRAM PLAN, TASK AREA 3-8

TASK 3-8.1 PROGRAM IMPLEMENTATION

TASK 3-8.2 DESIGN TECHNOLOGY

$\mathrm{A}-1$

TASK 3-8.4 FABRICATION TECHNOLOGY

$\mathrm{A}-4$

A-9 


\section{INTRODUCTION}

C F Braun \& Co has been awarded a contract (AT (04-3)-781) by the US Atomic Energy Commission for the development and verification of a Piping Design Guide for liquid-metal cooled fast breeder reactor power plants (LMFBR). The work is a Priority 1 Task under the LMFBR Program Plan (1) * prepared for the USAEC Division of Reactor Development and Technology (RDT) by the LMFBR Program office, Argonne National Laboratory. It is identified in the Program Plan as Task 3-8.2, Development of Design Technology for Piping, although as described herein the sub-tasks to be pursued under this contract do not necessarily have a one-for-one correspondence with those envisioned by the Program Plan.

Figure 1-1 shows the interrelationship of tasks under Task Area 3-8, Coolant Transport and Storage Systems, of the LMFBR Program Plan. Figure 1-2 shows the corresponding interrelationship of sub-tasks as now planned under this contract. A comparison reveals that the overall objectives of Task $3-8.2$ of the Program Plan are met in full, together with certain of those under Task 3-8.4, Development of Fabrication Technology.

This Technical Report describes the overall objectives of the LMFBR Piping Design Guide, and discusses both the concept and the implementation of the steps considered necessary for its development and verification. The detailed work plan is presented, together with the tentative schedule and organization chart. A review procedure, established by USAEC and LMEC, is described, and the manner in which identified $R \& D$ requirements will be handled has been included. An Appendix containing pertinent sections from the LMFBR Program Plan having a direct bearing on the formulation of the Piping Design Guide has been added.

The objectives of the LMFBR Program Plan are discussed in section 2 of this report. However, it will be appropriate here to discuss the underlying motivation for the Program.

It has been estimated that the Nation's electric power needs are doubling every ten years or so. With a diminishing potential in the United States for hydroelectric and fossil-fuel power, a great part of this new demand will have to be met by nuclear power plants. By mid-1968 the total utility generating capacity in the us was a staggering $272,000 \mathrm{Mw}(1 \mathrm{MW}=1,000,000$ watt), of which only a mere 3,000 Mw was being met by nuclear power. Nuclear plants now under construction, or already committed, will boost this to about 73,000 Mw, and by 1980 nuclear power capacity will have reached around $160,000 \mathrm{Mw}$, with conventional power plants producing an

* References are listed numerically in section 11, Bibliography 
additional $115,000 \mathrm{Mw}$. These statistics show that the nuclear power industry not only has to overtake, but must far outstrip, the growthrate of the conventional power industries.

Standing in the way of achieving these goals is the problem of supplying enough fissionable fuel to feed this great nuclear capacity. Present-day nuclear power plants, such as Yankee, Dresden, and San Onofre, have water-cooled thermal reactors which use natural uranium fuel (U-238) which is enriched to a level of some 3 to 4 percent with the fissionable isotope, U-235. Natural uranium contains only about 0.7 percent of U-235. High-grade sources of natural uranium are scarce, and would soon be depleted at the rates of consumption implied by the predicted growth-rate. The solution to the fuel supply problem appears to lie in the Fast Breeder Reactor, which has the ability to produce more fuel than it consumes.

Nuclear energy is released when an atomic nucleus is struck by a neutron, the nucleus splitting into two lighter nuclei and emitting two or more neutrons, along with gamma radiation and other particles. The U-235 isotope of uranium is the only source of fissionable material found in nature. But it happens that U-238, while not fissionable itself, can be converted artificially into a fissionable isotope of the recently-discovered man-made element Plutonium, Pu-239. Another artificial fuel can be made by converting Th-232 to fissionable U-233.

Although U-238 and Th-232 will undergo fission by reaction with highenergy (fast) neutrons to produce $\mathrm{Pu}-239$ and $\mathrm{U}-233$, the neutrons produced do not have a sufficient probability of fission to sustain the chain-reaction necessary for nuclear power generation. U-233, $\mathrm{U}-235$, and $\mathrm{Pu}-239$, on the other hand, do produce high-energy neutrons: for every neutron absorbed by reaction, U-235 produces an average of 2.5 new fast neutrons; U-233 yields 2.7 new neutrons; and Pu-239 produces 2.8 new neutrons. Since only one new neutron is required to maintain a chain-reaction, there is thus a resultant surplus of neutrons. In thermal reactors the surplus neutrons are wastefully absorbed by the surrounding environment. In the breeder reactor, however, surplus neutrons are absorbed in U-238 or Th-232, yielding a fissionable $\mathrm{Pu}-239$ or U-233 nucleus, thus actually producing more fuel than is consumed in the process. By reprocessing spent U-238 fuel, the fuel cycle can be made self-sustaining. It is estimated that the doubling time of an LMFBR might be as low as 7 years or less, well inside the predicted ten-year doubling period of the consumption rate. 


\section{INTRODUCTION Continued}

To achieve the breeding capability, the LMFBR has to be designed with a high concentration of fissionable nuclei and with a minimum of wasteful neutron absorbtion. They must therefore be relatively small in size with a high core temperature, necessitating a much higher cooling rate than is needed in thermal reactors.

In order to attain more efficient core cooling, liquid metals have been successfully tried as coolants. A mixture of sodium and potassium ( $\mathrm{NaK}$ ), and sodium alone, have both been tried, with sodium proving to be the most advantageous in terms of high heat transfer rates and low corrosion properties. An important part of the LMFBR Program, therefore, is concerned with developing sodium-handling technology to the point where huge quantities (up to $120,000 \mathrm{gpm}$ ) can be safely handled at temperatures up to $1200 \mathrm{~F}$, around the reactor circuit and through the intermediate heat exchangers and steam generators which comprise the power generating system of the fast breeder.

The feasibility of the fast breeder reactor has already been proven in a number of small test facilities in the United states and Europe. These are listed below.

$\underline{\text { NAME }}$

United States

UK (Scotland)

France

USSR

*Clementine
*LAMPRE I
*EBR-I
EBR-II
Enrico Fermi
SEFOR

Dounreay

Rapsodie

BR-2

BR -5
POWER (Mwt)

0.025
1.0
1.4
62.5
200
20

60

20

0.1

5.0

*Subsequently decommissioned

In the United States, a seventh fast-flux test facility (FFTF) is in the design stage and will have a rated output of 400 Mwt when it goes critical in 1974. Others are also being planned in Europe, notably in the UK (PFR, 600 Mwt), France (Phenix, 600 Mwt), Germany (Na-2, 750 Mwt), and USSR (BN-350, $1000 \mathrm{Mwt})$. 


\section{INTRODUCTION Continued}

Other reactors that have successfully utilized sodium as a coolant are the thermal reactors SRE and HNPF and the German KNK reactor.

Under the LMFBR Program Plan, the initial objective is the construction, by the mid 1970's of one or more demonstration plants in the 300 to 500 Mwe range, with an ultimate objective of providing technology for commercially feasible plants in the 1000 Mwe size range for the late 1980's. If successful, the demonstration plants would do much to furnish the high degree of confidence considered necessary to assure the utility industry that the large investment required to build and operate LMFBR's on a commercial scale is justified, and to allay public concern over the safety of such plants. 


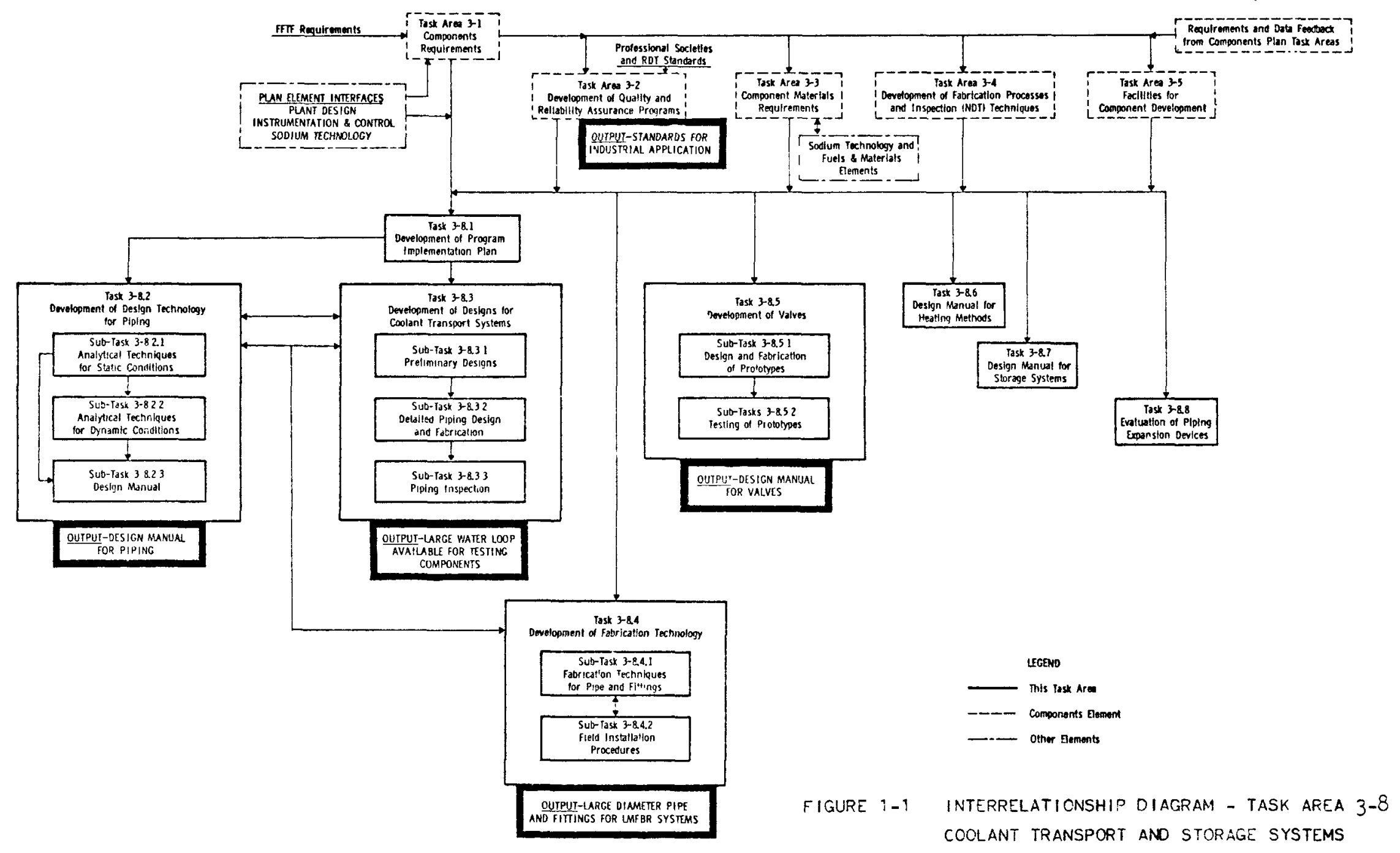




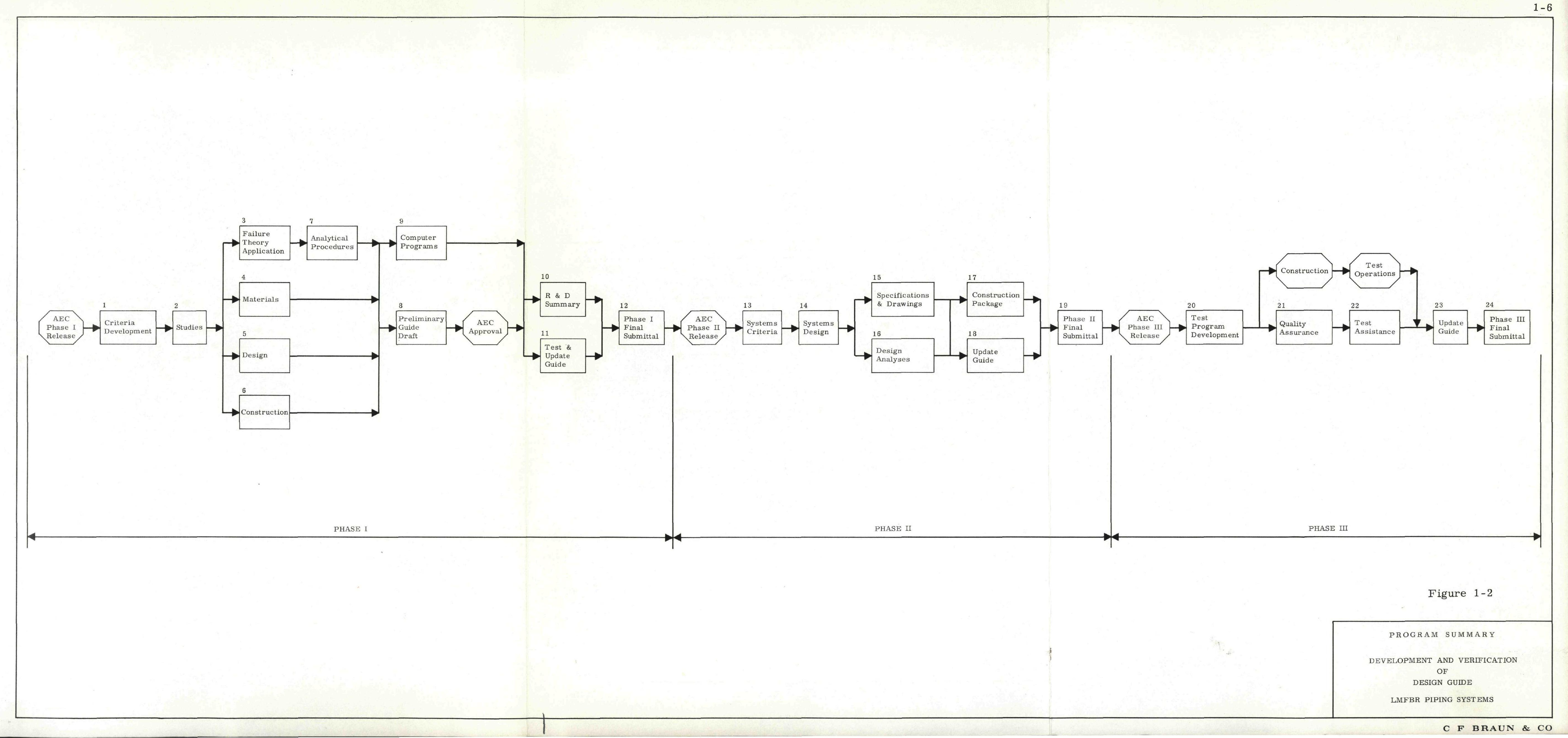




\section{LMFBR PROGRAM PLAN}

Milton Shaw, Director of RDT, has outlined the objectives of the LMFBR Program Plan in a Foreword to Reference (1), which is reproduced below.

In 1945 Enrico Fermi observed that: "The country which first develops a breeder reactor will have a great competitive advantage in atomic energy." To obtain this advantage, the nuclear community in the U.S. has been working for over 20 years to meet the recognized important objectives of economic nuclear power and improved fuel utilization through the development of the liquid metal fast breeder reactor. Most of this effort was experimental in nature and was conducted in our national laboratories. During the greater part of these two decades, the nuclear community, including the AEC, reactor designers, component manufacturers and the utilities-occupied principally with the development and marketing of the light water reactor-maintained a dispersed and minimal effort on the breeder.

However, significant changes have occurred in the U.S. nuclear power program within the past three years. These have been brought about through remarkable advances in the promise of nuclear power and the widespread acceptance of nuclear power by the U.S. utility industry as a new source of electrical energy. The resultant unprecedented demand for the light water reactor power plants, starting in 1965 , paralleled by greatly increased uranium demands and by projected large-scale plutonium production, has necessitated a more directed and concerted effort on a unified breeder development program. Consequently, the U.S. has established, as have many other countries, the Liquid Metal Fast Breeder Reactor (LMFBR) program, using sodium coolant, as the priority effort which will lead to large-scale commercial acceptance of the breeder.

During this period of change there has been increasing awareness of the critical dependence of our industrial and domestic complexes upon the timely availability of reliable electric generating plants. Further, there has been a growing recognition of a matter crucial to the successful development of any type of nuclear power plant--the achievement of demonstrated reliability through strong and disciplined engineering and quality-assurance programs, and through growing experience. No longer is there any question that careful and systematic 
planning and high standards in each phase of development, design, construction, inspection, test, and operation of nuclear power plants are essential to provide the safety, reliability, and economics needed for utility operation. The best technical competence and the strongest possible management must be available to focus our resources on the planning and production of successful nuclear power plants. Many changes will have to be made, both in the laboratories and in industry, to effect the transition from general development tasks to priority development programs and from light water reactors to LMFBRs. Such changes are needed to strengthen and provide definitive guidance for the technical sector of the community to properly emphasize, direct and coordinate the timely planning and implementation of the program.

In recognition of these programmatic and technical needs, the AEC initiated extensive preparation of the LMFBR Program Plans in 1966. Input from successful experiences with other largescale nuclear power development programs has been used in the program scope, technical management, planning, available resources and use, implementation and priorities.

Sufficient experience exists to provide assurances that each complex element of the LMFBR program, if carefully pursued in a diligent and disciplined manner, can produce a viable industrial capability which will provide LMFBR plants on a self-sustaining competitive basis, at a minimum cost, and in a timely manner. On the other hand, there is sufficient experience available with less difficult and less complex projects and programs to demonstrate conclusively that timely, successful and economic resolution cannot be obtained by other than such disciplined programmatic efforts.

Consistent with the position taken in the 1962 Report to the President on Civilian Nuclear Power, increased emphasis is being placed on the role of the AEC in exercising positive and vigorous leadership, both to achieve the LMFBR technical goals and to assure sufficient participation by the equipment manufacturing and nuclear industries. We are indeed fortunate to have extensive facilities, some excellent and others being improved, and other resources needed to pursue successfully the LMFBR program. Generally speaking, the AEC will participate directly in the development of LMFBR technology, working through its own laboratories and the industrial contractors, and with the utilities. Cooperative programs will be used, 
where possible, for LMFBR engineering efforts and demonstration reactors, bring to bear the developing industrial capability and the utility interest through direct participation and sharing of the required investment and associated responsibilities. In discharging its responsibilities, the AEC also intends to place particular emphasis, in cooperation with industry, on the development and application of continually improving standards of design, construction and operating practices for LMFBR projects and programs.

The many recent changes by participating organizations to strengthen, augment and focus their capabilities give us confidence that the direction we are taking currently in the LMFBR program is essential and correct. The major job still lies ahead and actual experience over the past two years in many parts of the program reinforces the need for additional changes and strengthening actions.

Nothing should prevent the United states nuclear power community from achieving the goal of a safe, reliable and economic LMFBR which will fulfill the overall objective of economic nuclear power in increasing areas of this country and the world at large--provided we adhere to our plan of action and insist on the highest possible standards of engineering and workmanship.

\author{
Milton Shaw, Director \\ Division of Reactor Development \\ and Technology \\ U. S. Atomic Energy Commission
}

The Program Plan is described in detail in the ten volumes of Reference (1). Volume 1 describes the overall scope and objectives of the plan, while the other nine volumes are devoted to a detailed discussion of each of the principal technical elements of the programplant design (Volume 2); components (Volume 3); instrumentation and control (Volume 4); sodium technology (Volume 5); core design (Volume 6); fuels and materials (Volume 7); fuel recycle (Volume 8); physics (Volume 9); and safety (Volume 10).

The plan for each technical element has been developed in a uniform manner and comprises an assessment of the state of the art for its particular area of technology, a definition of the objectives of the tasks identified in the element together with their appropriate criteria and requirements, and a description of the steps considered necessary for meeting the objectives in a timely manner, including schedules and estimated costs. 
As the many tasks identified in the Program Plan get underway, the elements of the Plan will inevitably come into sharper focus, as will be reflected in new editions of the Program Plan documents from time to time.

The development and verification of the LMFBR Piping Design Guide, and the closely-related task of developing fabrication technology, are discussed in Volume 3, Components, of Reference (1). The significant paragraphs, wherein these tasks are described, are reproduced in the Appendix to this Technical Report.

In formulating a detailed work plan for the development of the LMFBR Piping Design Guide, the authors have kept their sights on the Program Plan objectives, deviating from the steps originally devised in the Plan only where it seemed to them desirable to develop supplementary information or to explore additional avenues of piping technology. It is for this reason that certain aspects of fabrication technology have been introduced in this present project: it was considered essential to the establishment of geometric constraints, and to the formulation of meaningful design methods. The implications of these considerations are more fully discussed in later sections of this Report. 
The first essential step in the development of the LMFBR Piping Design Guide is the establishment of LMFBR system requirements. This is necessary in order to set bounds to the scope of the Guide, with respect to environmental conditions as well as to the extent of the piping systems to be covered. While the LMFBR is in its formative stage of evolution, it is recognized that many of the parametric considerations will be subject to frequent change. However, since the Guide must clearly be capable of covering all LMFBR design concepts, it is necessary only to establish the upper and lower limits to the design parameters. In its Request for Proposal (RFP) dated May 7, 1968, the New York Operations Office of USAEC enumerated certain general requirements for the Guide, as follows.

1) Piping sizes up to 48-inch nominal diameter

2) Internal pressure $10 \mathrm{psia}$ to $225 \mathrm{psig}$

3) Liquid sodium temperature up to $1200 \mathrm{~F}$

4) Single and multiple configurations of straight pipe and fittings

5) Radiation $108 \mathrm{r} / \mathrm{hr}$ gamma field

6) Plant design life about 30 years

7) Plant operating cycles 1,000 to 10,000 startup and shutdown

8) Temperature transients $1200 \mathrm{~F}$ operating - 300 cycles at $-20 \mathrm{~F} / \mathrm{sec}$ for $15 \mathrm{sec}$ 25 cycles at $-30 \mathrm{~F} / \mathrm{sec}$ for $10 \mathrm{sec}$ $800 \mathrm{~F}$ operating - 300 cycles at $-10 \mathrm{~F} / \mathrm{sec}$ for $30 \mathrm{sec}$ 25 cycles at $+25 \mathrm{~F} / \mathrm{sec}$ for $10 \mathrm{sec}$

Tables 3-1-I and 3-1-II in Volume 3, Components, of the LMFBR Program Plan (1), identify a much broader set of component requirements.

The tentative data in these tables are representative of IMFBR concepts as they stood in early 1968. As work progresses on FFTF and the 1,000 Mwe demonstration plant designs, it is to be expected that the ranges of certain of the parameters listed may change. As more refined data becomes available, appropriate revisions will be made to the tables. Meanwhile, they will serve as a starting point for Design Guide development. 


\section{LMFBR SYSTEM REQUIREMENTS Continued}

Besides identifying ranges in component design parameters, it is necessary also to establish other general requirements for LMFBR systems. Among these are the following.

1) Interface Requirements - What constraints are imposed on piping design by the requirements of interfacing components and equipment (eg, reactor, IHX, pumps, valves, etc)?

2) Piping - What consideration shall be given in the Guide to piping component geometries? What kinds of components will be encountered? Is double containment to be considered? What are the pipe support requirements? What materials shall be considered? What effect does sodium purity have on material properties?

3) Preheat and cooldown - What are the preheat requirements for LMFBR coolant loop piping? What effect will they have on piping design? What preheat and cooldown rates may be anticipated?

4) Insulation - What insulation materials are suitable for sodium piping? How shall they be attached?

5) Leak Detection - What constraints on piping design are imposed by leak detection methods? What minimum leak rates are to be detected? How may leak detection equipment be monitored?

6) Fabrication and Erection - What methods of welding may be employed in LMFBR piping? How may inert gas purging be maintained in large diameter piping during welding? What testing procedures may be considered adequate for LMFBR piping at each stage of fabrication and erection?

7) Quality Assurance - What measures are to be prescribed to assure the integrity of LMFBR piping systems?

The questions posed above are not exhaustive: in the course of the development of the Guide other considerations will doubtless emerge and will have to be satisfactorily answered. It has to be recognized also that not every LMFBR system requirement will become significant to the Design Guide; on the other hand, unless they are first identified their significance cannot be properly evaluated. 


\section{LMFBR SYSTEM REQUIREMENTS Continued}

The first task under the present work plan for the Piping Design Guide is the preparation of Technical Report Number 110, LMFBR System Requirements for Sodium Piping. In the preparation of Report 110, each of the identified system requirements will be reviewed and delineated. In reviewing these requirements, reference will be made to the LMFBR Program Plan, as well as to such sources as LMEC, LMIC and NSIC. Due note will also be taken of the requirements for the Sodium Pump Test Facility (SPTF), which facility Braun is currently designing for LMEC. In addition, information will be sought from the conceptual designs of the ANL 1000 Mwe Follow-on studies, and the developments of the FFTF currently in the preliminary design stage.

(NOTE - At the time of writing, Technical Report 110 had already been issued in preliminary form for review and comment. It will be periodically updated and reissued as information from the other LMFBR program studies and facility designs becomes available.) 
In order to establish the extent of the primary and secondary coolant loop piping to which the Design Guide will be applicable, it will be appropriate to review the LMFBR concepts at present being considered.

The LMFBR essentially comprises a relatively small and compact reactor core and fuel-control configuration, cooled by the upward flow of primary liquid sodium. Heat from the primary coolant is removed in an intermediate heat exchanger (IHX), and the coolant is then recycled back to the core by a primary pump. This circuit comprises the primary coolant loop. In the IHX, heat is transferred to a secondary sodium loop wherein the sodium is circulated by a secondary pump from the IHX to a steam generator and back to the IHX.

The use of the IHX is considered necessary as a safeguard to reduce the probability of an accident in which radioactive material may be released. The primary sodium which removes heat directly from the reactor core will contain radioactive material and thus it is necessary to assure containment of this material in the event of an accident. By providing a secondary sodium stream which exchanges heat with the primary sodium, the heat from the reactor can be utilized to generate steam in a non-radioactive environment. The consequences of a possible accident resulting from a sodium-water reaction in the steam generating system are thus reduced by having non-radioactive sodium as the heating medium. The cessation of flow of the secondary sodium due to a failure of that system, while naturally calling for an immediate shutdown of the reactor, would give rise to a less violent temperature excursion in the reactor than would be the case if the primary loop similarly failed. By locating the IHX in, or immediately adjacent to the reactor, the severity of the consequences of a primary loop failure can be minimized.

Two basic design concepts have so far been evolved - the 'pot' (or 'pool') concept; and the 'loop' concept.

In the 'pot'-type system, the primary pump and IHX, together with the primary coolant piping, are located entirely within the reactor core containment vessel. The secondary pump and steam generator are located outside, the secondary coolant loop thus passing through the containment vessel wall to and from the IHX.

In the 'loop'-type concept, on the other hand, the primary pump and IHX are located outside the reactor containment vessel, the primary coolant piping passing through the vessel wall.

There are arguments in favor and against both concepts: each is being studied with almost equal attention at the present time, and it will be necessary that the Design Guide be formulated to cater to both concepts. 
Figure 4-1 shows the general arrangement of a 1000 Mwe pot-type conceptual design developed by Advanced Products Operation, General Electric Company, Sunnyvale, California (2).

Figures 4-2 and 4-3 show the loop-type design of a similar 1000 Mwe concept by Atomics International, North American Rockwell Corporation, Canoga Park, California (3).

Figure 4-4 is an artist's impression of the Sodium Pump Test Facility now being designed by C F Braun \& Co for LMEC. The SPTF, although not typical of LMFBR concepts in piping configuration, is being designed to meet environmental conditions very similar to the LMFBR, except that it will not be a radioactive system. Capable of handling up to $120,000 \mathrm{gpm}$ of liquid sodium at temperatures up to $1200 \mathrm{~F}$, and of being subjected to severe thermal transients, SPTF incorporates the most advanced concepts in liquid metal technology, and will provide much valuable information in support of the conceptual design of such systems.

A comparison of the 'pool' and 'loop' configurations shows that the latter comprises a considerably more extensive primary piping system and presents a more difficult piping design problem. In the pool concept, the piping is totally immersed in the sodium pool, which in turn is enclosed beneath the shield plug (see Figure 4-1). If the primary piping should fail, there would be no loss of sodium inventory. 


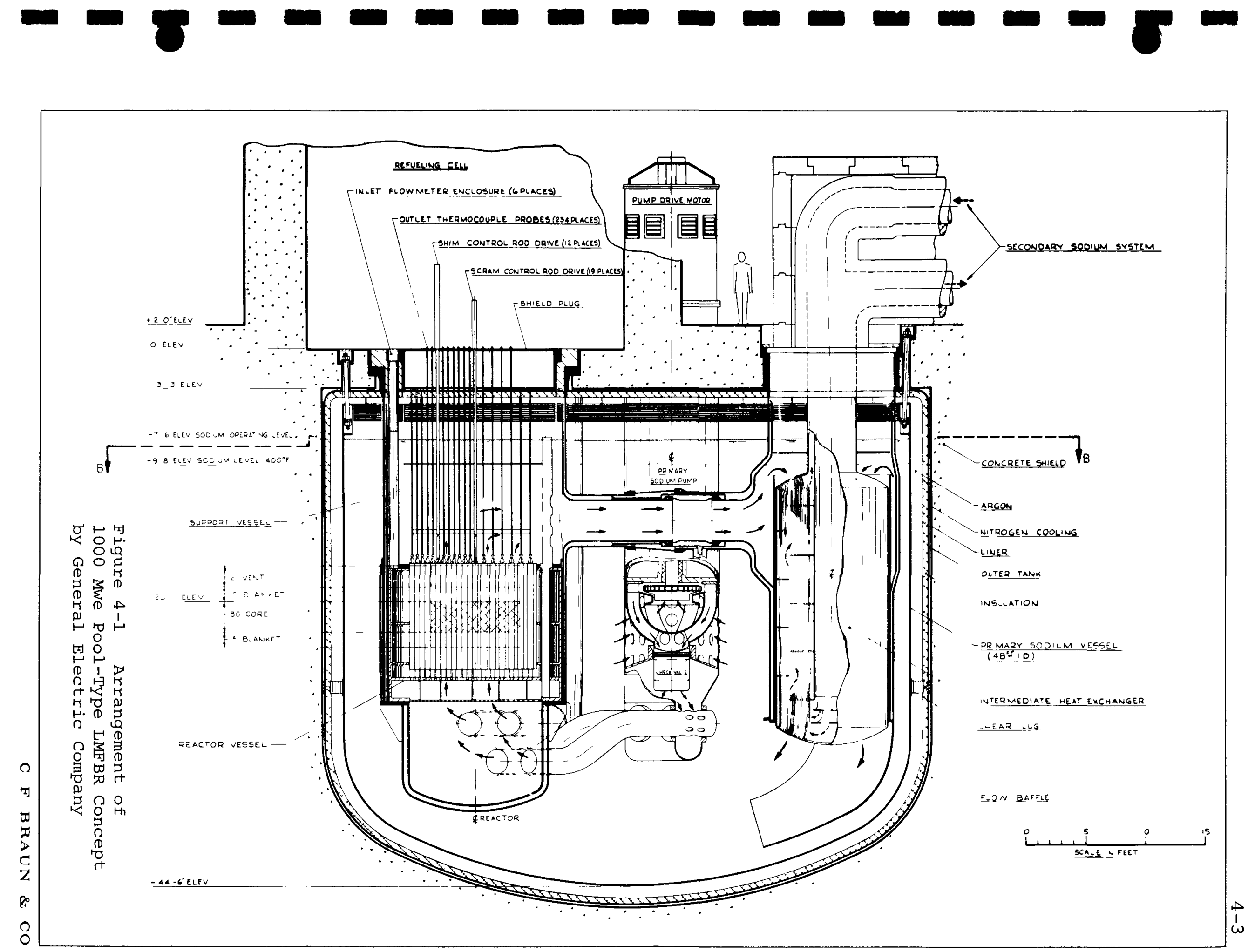



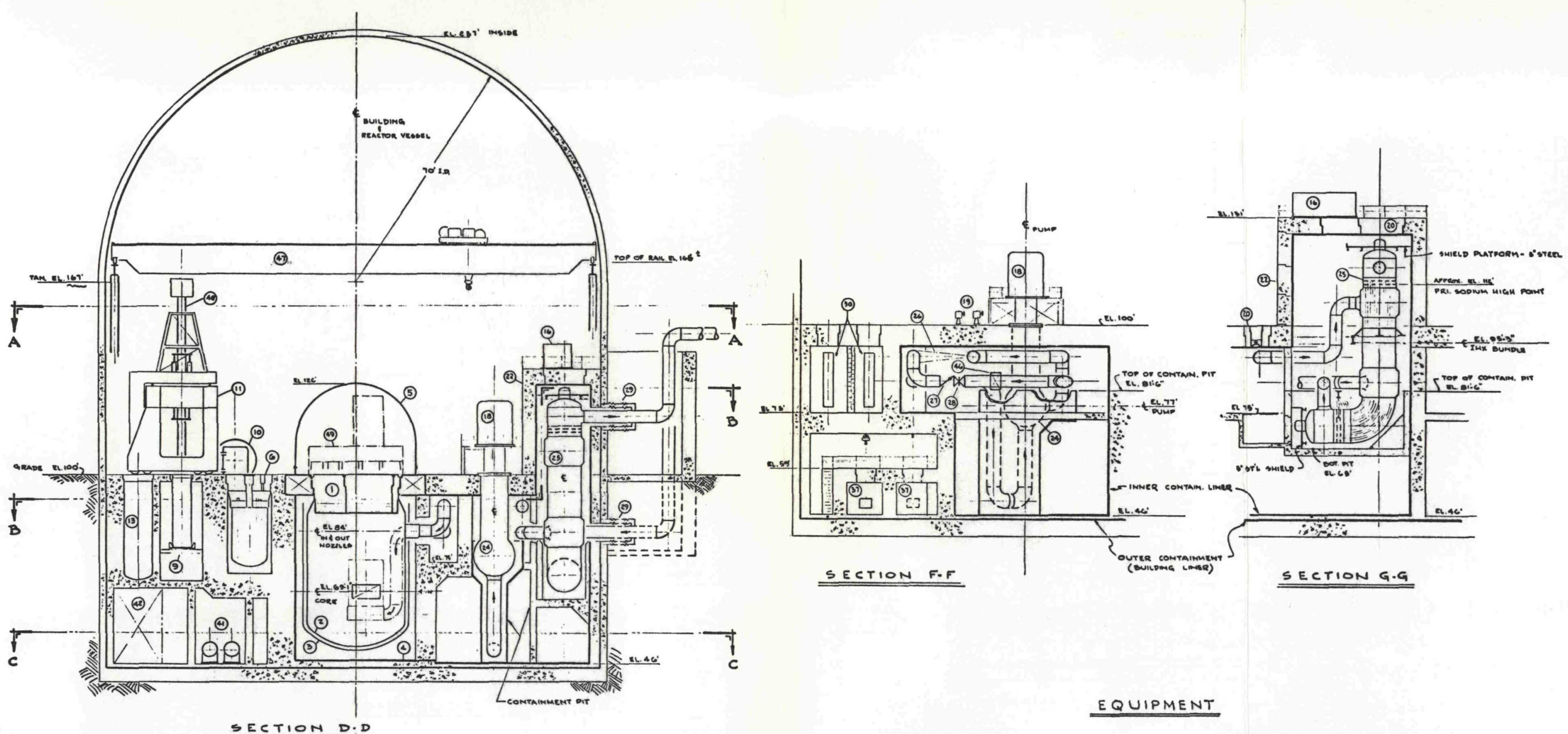

EQUIPMENT
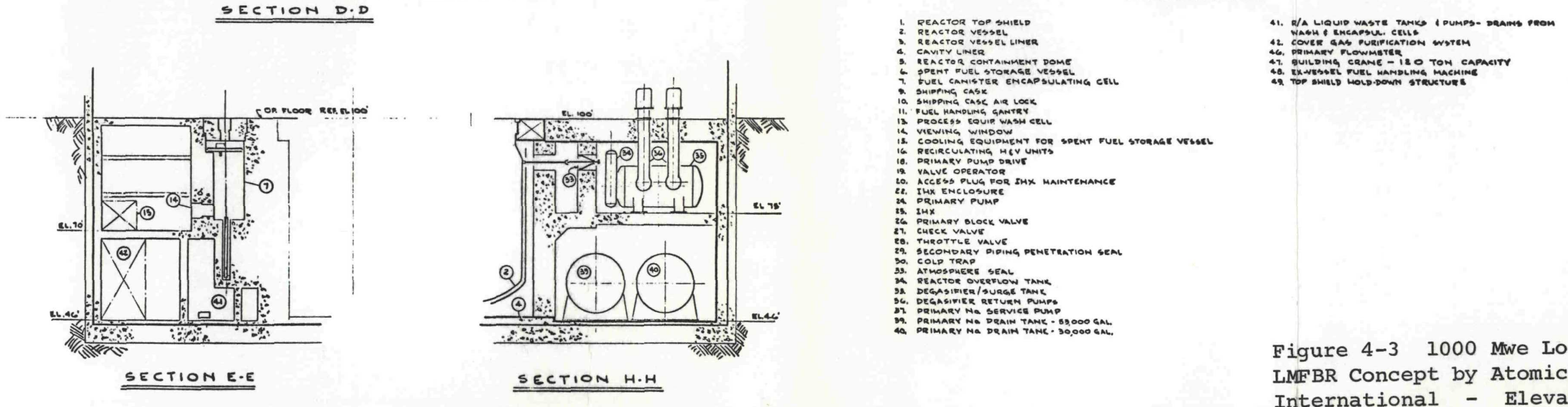

Figure 4-3 1000 Mwe Loop-Type LMFBR Concept by Atomics International - Elevations 


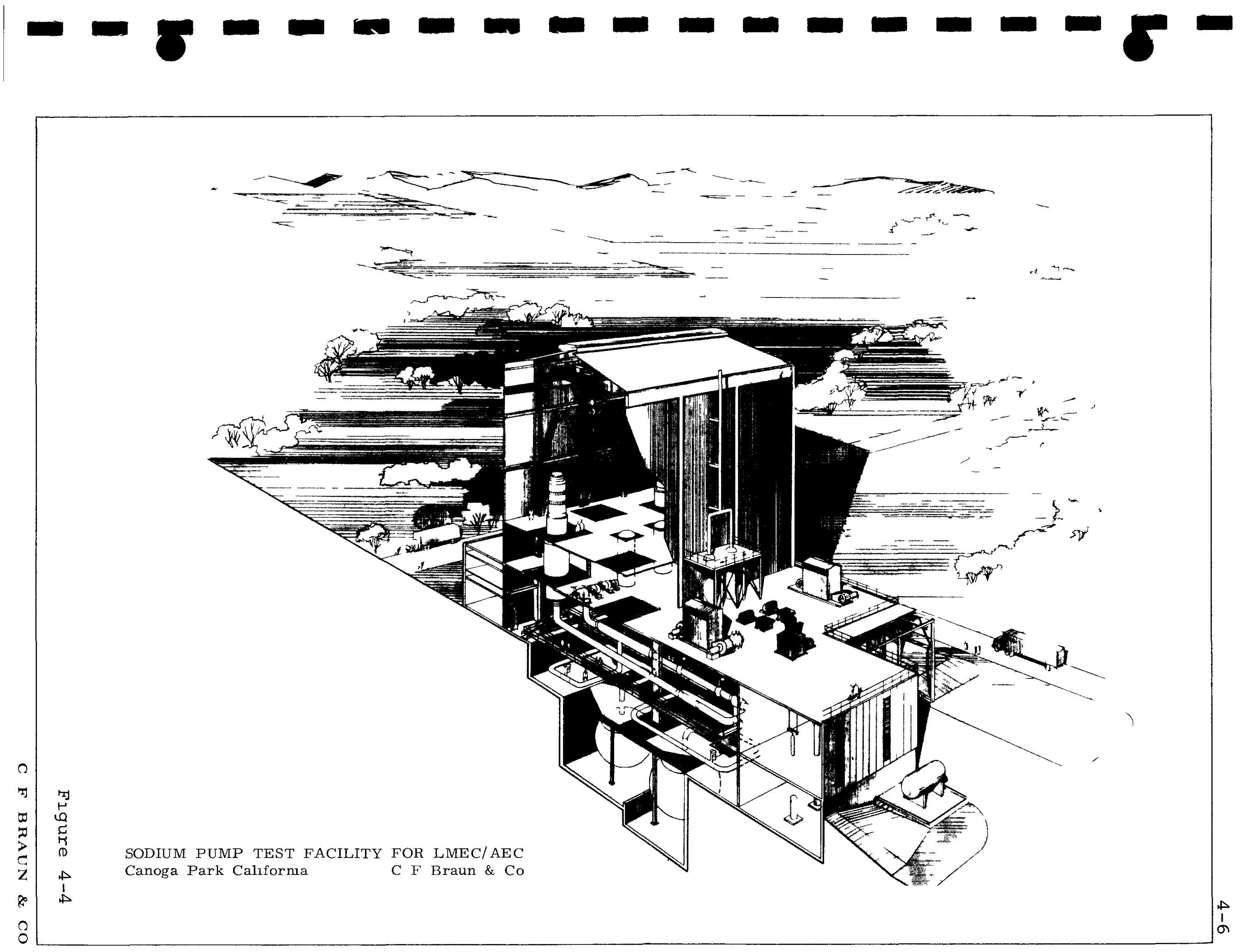




\section{DESIGN GUIDE OBJECTIVES}

The overall objective of the present task is the provision of a Design Guide document which will enable the piping engineer to design the primary and secondary sodium coolant piping systems for an LMFBR with confidence.

To this end the Design Guide must meet certain more specific objectives, as follows.

1) It must furnish guidelines and procedures that will direct the designer's efforts so as to assure the utmost integrity of design at each stage of development

2) It must steer the designer away from the pursuit of inappropriate or unreliable approaches to design, or the selection of improper materials or components

3) It must provide the designer with sufficient freedom from constraint as will permit design flexibility and encourage originality of concept

4) It must be written in language which the averaqe piping designer may be expected to understand readily without extensive reorientation or further technical education

5) It must avoid generalities which might leave the reader in doubt on specific matters, or require him to refer elsewhere for further guidance, except in instances where existing references are familiar and in general acceptance (eg, RDT, ASTM, and USASI specifications and standards)

6) It must be organized in a logical and orderly fashion. Tables and other data which the user may need regularly should be collected together to avoid irksome and time-consuming searching

7) Illustrative material should be of excellent quality and free of ambiguity. Worked examples, designed to take the user step-by-step through the analytical procedures, should be presented in a uniform manner using formats that could be standardized. The examples themselves should be based on realistic design concepts as similar as possible to those likely to be encountered in practice 
8) It is desirable that, wherever possible, new procedures that must be developed for the LMFBR environment should not depart radically from existing code procedures.

Rather, they should take the form of extensions to Code procedures, supplemented by rules covering their practical design application.

In setting out to acheive the above objectives, participants in the development of the Design Guide will be directed by certain guiding principles, which are worth summarizing here.

The attainment of the goals of the LMFBR Program Plan can be realized only by careful and systemmatic planning and high standards in each phase of development. This is just as true for each subtask as it is for the overall program. Much of the work of preparing the Design Guide will involve the careful study and review of existing practices in the light of the special needs of the LMFBR, and it will be very important that the practical considerations of eventual implementation in the Design Guide be kept constantly in mind. Each step must be planned as a logical development of that which preceded it, as well as that which will follow it. The work plan, which is described in detail in section 6 of this report, has been devised with these strictures in mind.

As now conceived, the preparation of the preliminary Design Guide, culminating in the trial use of the Guide on typical LMFBR piping concepts to be furnished by USAEC, represents completion of Phase I of a three-phase program. Phase II will entail a more thorough testing of the Design Guide by using it to prepare a construction package for representative piping systems selected by USAEC. Phase III will be the construction and test operations of piping systems designed under Phase II. Phases II and III are outside the scope of the present contract, and will be more fully defined at a later date. Provisional plans for Phases II and III are discussed in section 7 of this report. 


\section{GUIDE PREPARATION WORK PLAN}

The detailed work plan for Phase I, Development and Verification of Design Guide for LMFBR Piping Systems, is summarized in Figure 6-1, which also shows the relative interdependence of each task. In the following pages the objectives of each task are individually discussed.

TASK 210 - STUDY FAILURE THEORIES The various theories of failure will be reviewed and the areas of applicability, and the potential suitability as design bases identified. The output of this stateof-the-art survey will provide needed information for the other tasks aimed at establishing the rules and limits for the design of LMFBR piping systems. Failure theory considerations will include maximum principle stress (Mohr), maximum shear stress (Tresca), and elastic strain energy, (Von Mises), stress classification, and ratcheting.

Both Section III, and Section VIII, Division 2, of the ASME Boiler and Pressure Vessel Code, and USAS B31.7 use the maximum shear theory of failure as a basis. In the creep range there may be significant changes in the failure mode due to strain aging, heat treatment, etc, which may result in other theories of failure such as maximum stress to be considered in the design rules.

This survey will also include other relevant concepts such as the life-fraction concept as related to the accumulation of creep strains, the relationship of creep strain damage to fatigue damage, and the relevance of both strain cycled and stress cycled fatigue life. The latter item requires consideration since seismic and vibratory loading on piping is inertia type loading as contrasted to deflection imposed loading such as might result from thermal stresses. In other words, the emphasis is on satisfying load equilibrium rather than strain or deflection compability.

The Iimitations of Miner's hypothesis of a cumulative damage or usage factor will be reviewed for the condition where both stress and strain cycling exist over the component life. In addition to the technical literature, sources of information for this study will include the ASME Boiler and Pressure Vessel Subcommittee on Design (particular emphasis will be placed on close liaison with the subgroup on elevated temperature design where applicable studies are in progress), the Pressure Vessel Research Committee, and the RDT reactor standaras program. 
6 GUIDE PREPARATION WORK PLAN Continued

TASK 211 - SELECT FAILURE THEORIES Based on the studies of Task 210, selection of the failure theories to be used as the basis for evaluating structural adequacy will be made. Consideration of system loadings and the expected failure modes associated with these loadings will be included as part of the failure theory selection. This task of necessity will include a preliminary evaluation of methods of applying the failure theories, since some theories, such as the Von Mises, may result in unwarranted analytical complexity and may be impractical from a design standpoint.

The results of Tasks 210 and 211 will be summarized in Technical Reports 210 and 211 respectively.

TASK 214 - PIPING FAILURES Incidents of piping failures will be tabulated and categorized with a view towards establishing guides to preventing similar failures in the future. Of interest will be large and small pipes made of the materials listed under Task 315 . While piping for many applications will be considered, major emphasis will be placed on failure experience in high temperature service. Particular attention will be given to failures in sodium piping systems.

Typical causes for incipient and actual failures which have been reported for sodium piping are, slag or other inclusions in the pipe material, poor welds, and thermal fatigue cycling in mixing tees. A failure in a drain pipe which has recently been discovered at the Dounreay Fast Reactor point to the need for maintaining controlled, non-corrosive atmospheres in sodium piping at all times. Intergranular attack observed by the General Electric Company in the "cross-over piping" of several sodium loops may be similarly related. Piping failures due to excessive primary stresses have been relatively rare in sodium systems.

Since failures in sodium piping generally start as pin-hole leaks and grow relatively slowly, it is important to detect such leaks before a large amount of sodium is lost. For this reason, sodium leak detection methods, which might be considered integral with piping systems, will be reviewed under this task. Data on sodium leak propagation and performance experience with applicable leak detectors will be collected and evaluated.

Literature searches will form the basis for collecting information on pipe failures in general. LMIC is expected to be a prime source for information on sodium piping failures. Of particular value will be a review of incident reports which are being collected by the LMIC. In addition the study done by General Electric reported in GEAP 4574, Piping Failure study for Reactor Primary Coolant Pipe, will be carefully reviewed. 
TASK 214 - PIPING FAILURES Continued

The work done under this task will be reported fully in Technical Report 214. (Note - This Report was issued in preliminary form for review and comment on November 15, 1968).

TASK 217 - STUDY OF BASIS FOR EXISTING CODES During the past quarter of a century, much work has been done in the piping engineering field. While knowledge is admittedly incomplete in many areas, particulary in that relating to creep phenomena and incremental distortion, existing practices are quite naturally dependent upon the developmental work already done, and code Committees have leaned heavily upon it in the formulation of code rules.

In approaching the task of compiling the LMFBR Piping Design Guide, it is important to recapitulate the experimental and theoretical work that has gone on since about 1950 in establishing s-values, fatigue curves, flexibility and stress intensification factors, and other design criteria used in current code documents in related fields. Such a review would serve the two-fold purpose of consolidating and aligning the start-point and, perhaps more importantly, defining those areas in which uncertainty exists.

This study will entail a summation of the bases for the design rules in the present editions of the ASME Pressure Vessel code and the USASI Code for Pressure Piping. Source documentation will be referenced, and a critical analysis made highlighting both the strengths and the weaknesses of each.

The findings of this study, together with a review of their applicability to the LMFBR, will be summarized in Technical Report 217. (Note - Technical Report 217 was issued preliminary for review and comment on December 13, 1968).

TASK 220 - STUDY OF FABRICATION AND INSTALLATION REQUIREMENTS The fabrication and erection of LMFBR piping systems will require very careful consideration if design and analytical procedures are to be realistically established. It will be necessary to ensure the highest possible standards of workmanship, together with stringent quality control at every stage, and rigorous inspection and testing procedures.

This study will determine the depth of experience already reported for liquid metal systems, for existing nuclear and fossil-fuel power plants, and for other large high-temperature piping systems of comparable complexity. Data developed in Tasks 214 and 228 on materials, will be reviewed in this context to establish areas of special concern. The study will seek answers to the following questions, and others arising from them. 
MILL REPORTS What precautions must be taken to insure the integrity of physical and chemical properties of piping materials at the mill? Do existing procedures give the degree of quality assurance considered necessary?

DIMENSIONAL TOLERANCES Recognizing that LMFBR systems will comprise piping having $D / t$ ratios larger than those in present nuclear systems, problems of ovality, flat spots and other dimensional inaccuracies can be significant. What dimensional properties of pipe and fittings are of special importance? What shall be the permissible tolerances?

ENVIRONMENTAL CONSIDERATIONS Will clean room facilities be fequired at each stage of fabrication and erection? or none at all? And, if they are required, how stringently must the enviornment be controlled?

HEAT TRANSFER CONTROLS Are existing solution annealing procedures considered optimum for LMFBR piping? What steps must be taken to assure they are properly carried out?

HANDIING AND STORAGE What precautions are deemed necessary to protect piping and fitting from rough handling? Can wire rope slings and chokers be used, or must nonmetallic materials be used for these services? How shall openings in pipe and fittings be protected during transportation and storage?

WELD PREPARATION What methods shall be used for weld preparation? More importantly, what methods must be excluded? Is grinding considered harmful? And what are the tolerances on weld profile dimensions?

ERECTION REQUIREMENTS Identify the problems likely to be encountered during erection. Weather protection? Ambient temperature limitations? What special provisions for alignment, fit-up, cold spring? And for pipesupport and spring hanger settings? Is inert gas purging required?

DESTRUCTIVE AND NONDESTRUCTIVE TESTING To what extent can radiographic, ultrasonic, and dye penetrant test methods be used? What other methods could be applied to give meaningful quality control? Can dye penetrant residues be harmful? Is destructive testing justifiable? 
TASK 220 - STUDY OF FABRICATION AND INSTALLATION REQUIREMENTS Cont

INSPECTION Are Section III and B31.7 inspection methods and report procedures satisfactory for LMFBR piping systems? Do they need to be augmented with rules such as those in the AEC supplement to section III?

PRESSURE TESTING What testing fluids are acceptable and what shall be excluded? What, if any, are the effects of pressure tests on the cycle life of the system?

CLEANING Upon completion of erection, inspection and testing, what further precautions are necessary to ensure cleanliness of the system? Is chemical cleaning permissible? What solvents may be used, and what shall be excluded?

ELECTRODE VERIFICATION What steps shall be taken to avoid deterioration of weld rods? What precautions are necessary during storage? Are checking procedures needed to ensure proper selection of weld rods? Should ferrite content of weld rod be analyzed prior to use?

WELDING PROCEDURES Are suitable welding procedures developed for all of the candidate materials of construction? To what processes shall welding be limited? Are ASME Pressure Vessel Code qualification procedures adequate? If not, what a dditional tests shall be performed for welding operator qualification? Can stud welaing be permitted? And what records shall be maintained to identify the welder, and the test results?

POST-WELD HEAT TREATMENT What, if any, are the post-weld heat treatment requirements? What are the minimum holding temperatures and times? What supervision procedures are needed? What precautions are required to prevent excessive oxidation?

DRY-OUT PRECEDURES Are environmental controls necessary to minimize humidity and prevent sweating? How shall moisture be removed upon completion of erection? How can moisture removal be verified?

When satisfactory answers have been found to these questions, and to others which may present themselves during the course of the study, they will be fully reported in Technical Report 220 . 
TASK 223 - STUDY HEATING AND INSULATION METHODS

A study of heating and insulation methods will be made to determine practical methods and to define their effect on the piping system.

Specific heating requirements must be determined as part of the criteria development, Task 110. In general, we would expect this system to preheat piping to a temperature in the range of $350 \mathrm{~F}$ to $400 \mathrm{~F}$. If solidified sodium is in the piping, consideration must be given to a heating sequence permitting sodium melting to proceed away from a free surface. Heaters for smaller piping might be designed with a higher temperature capability to redissolve percipitation impurities.

Where there are piping connections between sources of sodium with extreme temperature differences, the possibility of designing a heating system which minimizes steep longitudinal gradients in the pipe must be considered. Other considerations include elimination of cold legs where cold trapping may occur, and melting of freeze seals when required.

A number of different heating methods will be considered in the study. They are summarized as follows.

INDUCTION HEATING The most economical and reliable form of induction heating for this type of application is the 60 hertz high flux density method. This method requires minimum maintenance, but must be designed empirically for each specific application. This method has a low efficiency with non-magnetic materials. Carbon steel jacketing of stainless steel, or other non-magnetic material, is desirable to improve the efficiency.

RESISTANCE HEATING Resistance heaters applied to the external surface of the piping provide a very practical method of heating with a high flexibility in the application because of the wide variety of sizes, ratings, configurations, and controls available. Reliability of this type of heating has been a problem in some applications. This can be overcome in part by redundancy of elements and by operating elements at reduced surface power density and voltage.

ANNULAR FLUID HEATING This type of heating is accomplished by circulating hot fluid through an annulus around the pipe. Suitable fluids may include air, inert gas, sodium or NaK, and some organic liquids. Selection of the fluid is determined by compatibility with the piping material and sodium, by the heating criteria, and by power and utility requirements. This type of heating may also satisfy the requirement for double containment of primary sodium. 


\section{TASK 223 - STUDY HEATING AND INSULATION METHODS Continued}

FLUID TRACE HEATING This heating method consists of circulating fluid through separate pipes wrapped around the sodium containment. Similar fluids to the annular fluid heating method could be used.

There are a number of other heating methods that could be used such as electrical direct series heating and radiant heating. These have disadvantages which appear to disqualify them from the LMFBR piping application. They will however be reviewed in the study to determine whether this in fact is true.

External insulation for the piping is not a major problem. A number of insulation materials are available and in use. The principal criterion is compatibility with sodium. A summary of suitable insulation materials will be summarized in the study, and special requirements for installation will be noted. This will include any requirements for removing moisture to minimize the fire hazard in case of sodium leaks.

The application of internal insulation will be carefully considered. Internal insulation is of primary importance in reducing thermal transient stresses in the piping wall. Such stresses become very high during rapid changes in sodium temperature because of high heat transfer rate from sodium to the pipe. An internal insulation or thermal barrier that will reduce the heat transfer rate will effectively reduce the transient thermal stress.

If an effective insulation can be used internally, the pipe wall temperature will also be reduced, minimizing steady state as well as transient thermal stresses. The principal problem with good insulating material is the compatibility with sodium.

If an effective insulation method cannot be found, the desirability of thermal barriers will be investigated. These barriers consist of layers of metal which have lower heat conductivity than the sodium. They do not contain pressure. The principal considerations in the use of such barriers are cost and methods of securing them to allow thermal expansion, while providing a reliable attachment. Attention must also be given to vent and draining the barriers. Such barriers provide traps for foreign material and can be source of pipe cracks if care is not taken in their design and installation.

TASK 224 - SELECT HEATING AND INSULATION METHODS Based on the study performed in Task 223, a selection of suitable methods of heating and insulation will be made. A description will be prepared to define advantages and disadvantages of each method, and guidelines will be prepared to define system requirements, installation, and quality assurance provisions for each selected method. 


\section{TASK 224 - SELECT HEATING AND INSULATION METHODS Continued}

Upon completion of Tasks 223 and 224, Technical Report 224 will be prepared in which the results of the study are reviewed and recommendations are made.

TASK 227 - DEFINE IMPACT OF HEATING AND INSULATION ON PIPING SYSTEM Each type of heating system has an effect upon the design of the piping system. These effects will be identified so that they can be considered in defining piping design and analysis requirements. The impact of the heating system on the piping may include some of the following.

GEOMETRIC CONSTRAINTS Annular fluid heating systems may cause physical restraint on the piping due to differential thermal expansion, and to the outer containment attachment.

HEATING STRESSES AnY stresses developed during heating must be included in the fatigue evaluation. Transient stress will result from rapid heating. Some heating systems may cause either transient or steady state hot spots resulting in local stresses.

ACCESSIBILITY Heating systems requiring maintenance will require provisions for accessibility.

TASK 228 - STUDY MATERIALS The information available on candidate materials for LMFBR piping will be identified under this task. The output of this state-of-the-art survey will provide needed information for Tasks 314, 315, and 316. This study will consider properties, environmental effects, and welding problems.

An example of material selection for sodium piping was made in a previous study. The study was concerned with the selection of materials for the main circulating system of the sodium Pump Test Facility (SPTF). It was concluded that Type $304 \mathrm{H}$ stainless steel is the most suitable material for this application. LMFBR sodium systems differ from the SPTF in that the material selection for the LMFBR steam generator in the secondary sodium system will be strongly affected by considerations of stress corrosion on the water side.

The system $\Delta T$ introduces carbon activity gradients, which cause carbon transfer from the higher to the lower temperature regions resulting in possible degradation of mechanical properties. Austenitic steels with lower carbon activities, such as Type 316 , 347 , or 321 stainless steels will, therefore, be preferred from this point of view, but structural stability problems and/or welding difficulties may outweigh these advantages. 


\section{TASK 228 - STUDY MATERIALS Continued}

Stress corrosion on the water side of the steam generator tends to eliminate austenitic steels for this application. Ferritic, lowchromium alloy steels are preferred, but their high carbon activity leads to carbon transfer from the ferritic to the austenitic steels on the sodium side. Their lower cost makes them attractive for use in cold leg piping of the secondary system, where they also show sufficient strength. Additions of carbide formers such as titanium will reduce the carbon transfer problems. Such materials are in use in other countries, such as Germany, but no ASTM standards or piping code values exist for them in the USA.

Emphasis in the study will be placed on compiling information related to the effect of environmental conditions on the piping materials. Carbon transfer and structural stability have already been mentioned.

The effect at elevated temperature of sodium and its common impurities on the surface and bulk pipewall can also change the properties of the piping, particularly creep and fatigue. Mass transfer can change the surface composition appreciably due to the different solubility in sodium of the alloying elements, principally nickel and chromium, at the highest and lowest temperatures of the system. The presence of oxygen causes preferential depletion of iron from the surface.

Another environmental effect results from reactions on the external surfaces of piping at temperatures up to $1,200 \mathrm{~F}$ which are exposed to air. Both the oxidation behavior of piping materials in air without insulation, and the influence of insulation and its impurities on the oxidation behavior are of interest.

The results of this important study will be summarized in Technical Report 228 .

TASK 231 - STUDY OF SYSTEM INTERFACES This study will be directed towards ascertaining the degrees of constraint imposed on the piping by the system interfaces identified in Task 110. Both qualitative and quantitative definitions will be sought for each, and their significance upon other design parameters will be established.

It is anticipated that the study will address itself to three broad areas of concern, (1) the fluid interface, (2) the equipment interface, and (3) the in-line component interface.

FLUID INTERFACE Sodium purity, flow rates and velocities, carbon migration, gamma heating, radiation levels, temperatures and pressures all clearly belong in this category. Others will undoubtedly present themselves in the course of Task 110. 
TASK 231 - STUDY OF SYSTEM INTERFACES Continued

EQUIPMENT INTERFACE Here we will be concerned with the physical interaction of the piping with its connected equipment. Piping load limitations upon rotating machinery will be considered and quantitative methods of evaluation sought. Similar attention will be given to vessel connections of every type.

IN-LINE COMPONENT INTERFACE Pipesupport clips, lugs, and other external attachments; heat tracing and insulation; instrument connections; and internal attachments such as heat-shields and baffles - these are the more obvious areas of study in this category. The significance of piping loads on valve operation will also be considered, an an attempt made to establish constraining parameters.

LMFBR PROGRAM INTERFACES Other components for LMFBR systems are currently under study or development. Design requirements for the piping interface with such components will be reviewed, where possible, with contractors performing the development studies.

The interface criteria established in this study will be incorporated in Technical Report 231.

TASK 234 - STUDY SCALE MODEL TESTING METHODS Some analytical procedures for piping analysis are extremely complex or may require simplifying assumptions to achieve a solution. Model testing or experimental stress analysis can be used to supplement analytical techniques where the confidence in the analytical approach is low or the component being analyzed is extremely critical.

There are a number of different types of model testing procedures that will be considered.

PHOTOELASTIC TESTS Photoelastic tests can be used to determine the governing boundary stresses in a model under an imposed load, such as pressure or mechanical force. This procedure has been used extensively by the Pressure Vessel Research Council for establishing stress intensitities in various types of vessel nozzles.

SCALE MODEL TESTS Scale models of components such as tees and elbows, can be tested in a simulated environment of pressure, loadings, and temperature. This is essentially a steady state test method with strain gages used to determine stress levels near critical points in the component. New scale model testing techniques may have to be developed where the effect of relaxation must be considered. 
TASK 234 - STUDY SCALE MODEL TESTING METHODS Continued

LIFE TESTS Fatigue tests are generally accomplished by application of mechanical stresses to a specimen or test component. However, the combination of both thermal and mechanical stresses are important to the fatigue life. It may be practical to perform model tests including both mechanical and thermal effects by designing the model to keep all dimensionless parameters the same as the full scale system. This means that a manipulation of scale factors must be accomplished. The validity of scaling factors where the state of stress is time dependent must be investigated.

Typical scale factors to be considered include dimensions, pressure, temperature, material properties, component heat transfer properties, fluid heat transfer properties, and time of transients.

Once a set of scale factors have been selected which give the same dimensionless parameters as the full scale system, a life testing program can be initiated. This testing program should include all types of thermal transients, pressures, flexibility loads, and superposition of these effects.

DYNAMIC TESTS Determination of dynamic response to forcing functions simulating shock and vibration can be accomplished through system model testing.

ANALOG MODELING Analog simulation of a system can be used to provide information on dynamic flow conditions. Such modeling can be used to determine pressure/time history resulting from fluid hammer, fluid flow instability, temperature transients in complex systems and system dynamic response to various forcing functions.

In addition to reviewing the applicability to piping design of the experimental stress analysis techniques discussed above, it may be possible to determine if such techniques could be used to establish stress indices and other component data. Such information will unquestionably be needed later in the development of the Design Guide.

Technical Report 234 will summarize the work done under this study, and make recommendations for such additional laboratory programs as may be identified.

TASK 237 - STUDY DYNAMIC ANALYSES Dynamic excitations on LMFBR piping systems include the steady state environmental and flow induced vibrations plus transient loadings due to sodium hammer, earthquakes, etc. Present methods for performing dynamic analyses of 3-dimensional, redundant, linear-elastic structures use matrix methods of elastomechanics to set up the analytical model of the system, and the responses are calculated from the equations of motion using a digital computer. 
TASK 237 - STUDY DYNAMIC ANALYSES Continued

Various techniques of setting up the dynamic model, such as finite element/lumped parameter by either the force method (resulting in flexibility matrix) or the displacement-method (resulting in stiffness matrix) will be reviewed, and the extent of applicability to the design procedure will be identified. The output of this survey will provide data to prepare the procedural guide necessary towards the ultimate solution of structural responses due to both transient and stationary dynamical excitations.

The various numerical procedures and techniques for computing the dynamic response of the system, such as modal methods and direct numerical integration will be included in the survey and review. Nonproprietary computer codes suitable for dynamic analysis will be identified in this study.

The work of the study will be incorporated into Technical Report 237 . (Note - Technical Report 237 was issued in preliminary form for review and comment on December 20, 1968).

TASK 240 - STUDY OF INSTABILITY Stability in liquid metal systems will be affected by creep at the elevated temperatures, as well as by the strain hardening properties of the materials, and by any change in physical properties of the materials due to the liquid metal environment. Additional problems of design are introduced by the very high full-to-empty weight ratios, and relatively low pressures in liquid metal systems, resulting in large-diameter, thinwalled piping. Elastic and inelastic buckling may occur due to combined high axial bending and compressive loads. Local yielding may occur at pipe supports, elbows, or tees because of relatively large concentrated loads applied to the thin-walled pipe.

Elastic stability must be considered for pipe sections under the effect of actual plastic constraints at junctions where they exist. The effect of creep on deflections and possible time-dependent buckling must be evaluated. Deformation and incremental theories of plasticity will be reviewed and their applicability evaluated. Modes of failure of typical piping configurations by instability will be studied, present methods of analysis reviewed, their applicability for use in Task 418 to establish procedures for instability analysis. A survey of applicable computer programs will be made and they will be referenced.

Information for the above study will be obtained as much as possible by reference to available literature. Other sources of advice in special areas include Subcommittees of the ASME and PVRC, and the RDT Reactor Standards Program.

Technical Report 240 will summarize the findings and conclusions of this study. 
TASK 243 - STUDY SURVEILLANCE METHODS It is recognized that methods that may be adopted for in-service surveillance of the primary and secondary coolant systems may have a pronounced impact on other design considerations. The selection of insulation methods, for example, is clearly dependent upon the need for accessibility to surveillance equipment.

Even more important, however, is the establishment of what such surveillance methods must monitor in providing continued assurance of system integrity once the system is in operation.

In pursuing this study, consideration will be given to

1) Leak detection methods

2) Strain-measuring techniques

3) Material surveillance

4) System performance logging methods

The results of this study will be reported in Technical Report 243 .

TASK 310 - DEFINE ALL POSSIBLE SYSTEM LOADINGS The information developed in this task and Tasks 312 and 313 will be used to prepare a checklist of possible system loadings and to construct a guide for classification of stresses similar to that of Table N-413 of Section III of the ASME Pressure Vessel Code.

TASK 311 - DEFINE FAILURE THEORY RESEARCH AND DEVELOPMENT REQUIREMENTS The objective of this task is to identify the R\&D required to complete, supplement, or confirm the selected failure theories and their range of applicability. Basic information on the $R \& D$ requirements will be developed in Tasks 210 and 211 .

Relevant work under other elements of the LMFBR program will be identified and recommendations as to how the basic program might be modified to meet the failure theory $R \& D$ requirements will be made.

TASK 312 - DEFINE ALLOWABLE STRESS LIMITS The objective of this task is to define the design stress limits which are applicable to each of the various stress categories. Before establishing these limits, the stress categories will be evaluated to establish if modification to the categories as contained in section III of the ASME Code and USAS B31.7 Code for Power Piping are necessary because of the requirements which LMFBR piping must satisfy. This evaluation of stress categories will be made using the loadings defined in Task 310 and information developed in the $2 x x$ study tasks. 


\section{TASK 312 - DEFINE ALLOWABLE STRESS LIMITS Continued}

In the absence of sound technical reasons for differences, it is desirable to retain design stress bases which are familiar to the component designers. In establishing the LMFBR piping system design rules, consideration will be given to making the categories of stresses as consistent as possible with those of Section III of the ASME Code and USAS B31.7 Code for Power Piping.

It may be necessary to assign two sets of limits. The first may be stress limits computed on an elastic basis to meet startup or shortterm conditions. For long term conditions strain accumulation limits may have to be established.

TASK 313 - ESTABLISH TENTATIVE THICKNESS CRITERIA The objective of this task is to prepare the procedures for making a tentative design of the piping system. Consideration will be given to developing guides to assist the designer in establishing wall thicknesses and configurations which will then be analyzed.

TASK 314 - MATERIAL RESEARCH AND DEVELOPMENT REQUIREMENTS The objective of this task is to define areas where sufficient information on materials of interest does not exist, and to indicate the R\&D required to provide firm materials data in the guide. Basic information on the R\&D requirements will be developed in Tasks 228, 315 , and 316.

Relevant work under other elements of the LMFBR program will be identified, and recommendations as to how the basic program might be modified to meet the materials $R \& D$ requirements will be made.

A potential area for Materials $R \& D$ is on the mechanical properties of carburized austenitic and decarburized ferretic steels at elevated temperature, since a preliminary survey has indicated that data are not readily available in the literature. This information is of interest for sodium systems coupling austenitic and ferritic steels where carbon transfer may occur.

The austenitic stainless steels containing high chromium contents will tie up carbon (carburization) while the low chromium alloys will decarburize.

TASK 315 - MATERIAL PROPERTIES Final materials recommended for LMFBR piping will be selected from the study in Task 228, and for each of these materials, available data on the following properties will be tabulated or represented graphically over the temperature range from $70-1200 \mathrm{~F}$.

1 Creep and stress-rupture data, for allowable stress limits at elevated temperatures. This data may also be used in a lifefraction design approach. 


\section{TASK 315 - MATERIAL PROPERTIES Continued}

2 Short time yield and ultimate strengths required for establishing allowable stress limits at temperatures where creep and stressrupture are not controlling.

3 Ductility, reduction of area and elongation, for use with approximate methods of fatigue life determination, and possibly in establishing maximum deformation limits under very extreme (fault) conditions.

4 Strain hardening coefficients for use in plastic instability or creep-buckling load determination.

5 Modulus of elasticity and mean and instantaneous coefficients of thermal expansion; also the products $E \alpha$ for use in thermal stress calculations.

6 Fatigue life, stress and strain controlled, for establishing fatigue design curves.

7 Impact strength, to assure safe design against fracture propagation.

8 Thermal conductivity and thermal diffusivity for calculation of steady state and transient temperature distributions.

9 Poisson's ratio at elevated temperatures.

Many of the above properties of the structural materials will be affected by exposure to a liquid metal enviornment, and the data must be obtained under conditions similar to those which will be encountered in service.

Manufacturing methods may significantly affect the properties of these materials despite a uniform chemistry and final dimensions. Therefore, each material should be specified as "plate," "forging," "casting," etc., and separate values provided for each category, if applicable.

For a given set of material properties, the type and percentage of impurities present in the liquid metal and cover gas should also be stated, since the strength of the steels in a liquid metal environment may be appreciably affected by the impurities.

The effect of long-time exposure on structural and property changes must also be considered, and length of exposure to any given

environmental condition will be included in the data. 
TASK 316 - DEFINITION OF CORROSION AND EROSION CONSIDERATION The effects of environment on the piping will be identified under this task. Environmental factors will include sodium on the inside of the pipe, air or oxygen-depleted gas on the outside of the pipe and radiation effects. Consideration will also be given to any effects resulting from special enviornmental conditions such as may pertain after sodium draining and during cleaning operations and repairs.

The detrimental effects of sodium and engineering consequences may be depicted as follows.

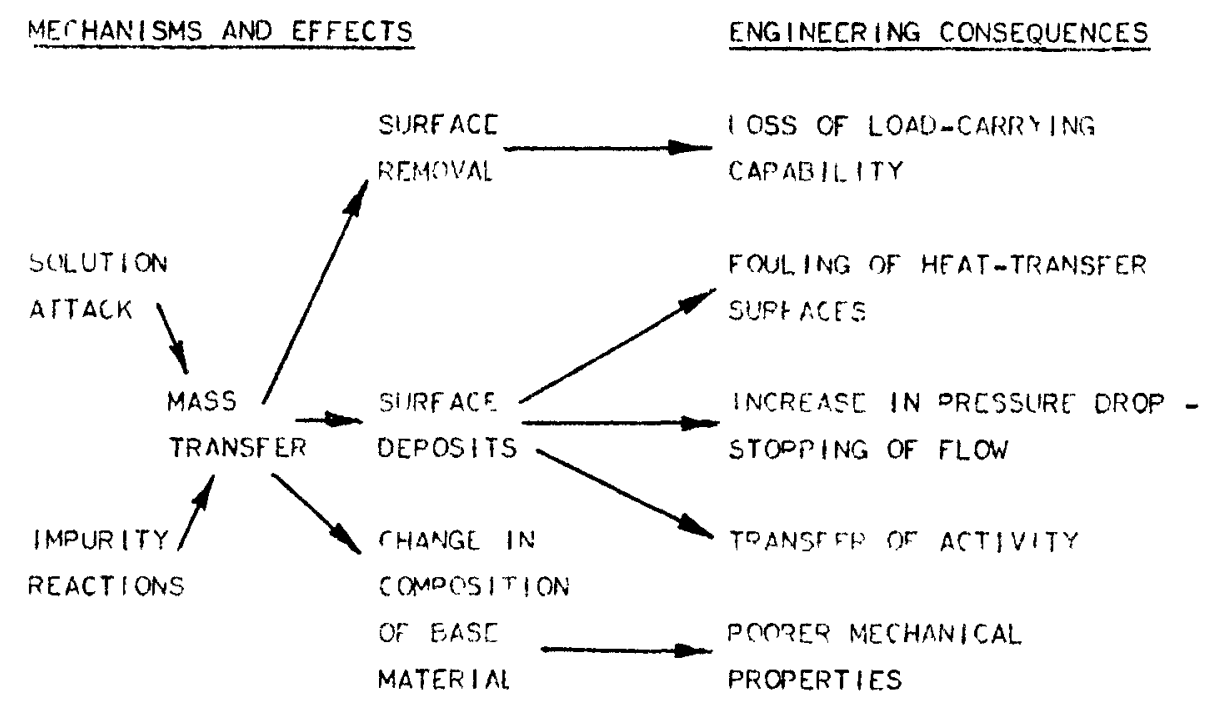

Available information on surface removal rates by sodium will be compiled as a function of operating variables for the materials of interest. Recommended values, to be used as a "corrosion allowance" will be supplied to Task 313. Similarly, information on surface deposits will be evaluated as input to the establishment of rules for pressure drop calculations and for estimating radioactivity under Task 313.

It is expected that mass transfer deposits will have little effect on pressure drop, especially in large pipes, but the transfer of radioactive species from the core region may delay access to primary system piping after the decay of $\mathrm{Na} 24$ following a reactor shutdown. 
TASK 316 - DEFINITION OF CORROSION AND EROSION CONSIDERATION COnt

A major effect of sodium environment is a change in composition of base material. A typical example is the carbon depletion of low chronium alloy steels and carburization of austenitic stainless steels in a system in which both types of steels are exposed to sodium. Such changes affect mechanical properties and will be evaluated as an input to Task 312 in which allowable stress limits will be defined. If, as expected, data are lacking for firm recommendations in certain areas, recommendations will be made via Task 314 for additional R\&D. values to be used in the interim will be given.

It is anticipated that the effects of the external environment on piping will be relatively minor. One exception might be an allowance for corrosion of low chromium-alloy piping at high temperature in air. Materials which may contact piping externally, such as insulating materials will be listed as either acceptable or nonacceptable.

A special effort will be undertaken to specify cleaning fluids and preservatives and to define material requirements for cleaning, storage, draining and repair operations.

The effects of gamma radiation on the mechanical properties of pipe materials is expected to be negligible although electrical insulation of heaters and other components of the "piping" may be affected. Gamma heating in stagnant pipes may be of concern.

TASK 317 - DEFINE DESIGN EQUATIONS The purpose of this task is to establish the relationships for the design of LMFBR Piping systems.

These relationships will include those for determinina the tentative thickness of a pipe wall for internal and external pressure, and compensation limits and configurations. Relationships which must be satisfied in order to meet the stress category limits developed in Task 312 will be developed for use in designing the system.

TASK 318 - ESTABLISHMENT OF GEOMETRIC CONSIDERATIONS The objective of this task will be to establish geometric criteria for LMFBR standard piping component geometries.

A study will be made of existing design practices and consideration given to the extrapolation of present USASI standard geometries out to the 48-inch size range. In adaition, a review will be made of nonstandard component geometries. Recommendations for the LMFBR standard will be made, and the testing required to develop standard design factors or stress indices will be identified.

TASK 319 - PREPARATION OF STANDARD COMPONENT GEOMETRIES In this task we will establish and draft standard dimensions for recommended LMFBR piping components using design criteria established in Task 318. 
TASK 320 - ESTABLISH RULES FOR FABRICATION AND ERECTION Data developed in study 220 will be used to write a standard specification for Fabrication and Erection of LMFBR Piping. This specification would be a sample of the basis of the contract for pipespool fabrication as well as the instruction for all fabrication and erection operations in the field. It would cover such subjects as (1) Definition of Responsibilities, (2) Special Handling Requirements, (3) Inspection, (4) Weld Procedures, and (5) Test Requirements.

TASK 321 - DEFINITION OF QUALITY ASSURANCE RULES The objective of the Quality Assurance procedures is to ensure that each step involved in the engineering and construction of an LMFBR Piping system meets three basic goals. These goals are, in order of importance, (1) safety, (2) reliability, and (3) maintainability.

In this task the level of quality assurance required in the engineering, procurement and construction activities, will be established. This will include the procedures necessary for the control and implementation of these quality assurance requirements. Existing $Q A$ programs in use for the LMFBR programs, such as for SPTF and FFTF, will be reviewed for applicability to the piping.

The scope of the quality assurance requirements will include specifications for all phases of piping design and construction. Included will be requirements for control of engineering and analysis, materials, manufacturing processes, erection, and testing. The responsibility of all parties will be delineated.

Proven control and surveillance procedures, such as those set forth in Military Specification MIL-Q-9858 A and NASA Specification NPC 200-1A, will be scrutinized and expanded to suit the exacting requirements of an LMFBR Piping system.

TASK 322 - DEFINE RULES FOR IN-SERVICE SURVEILLANCE This task will consist of specifying requirements for the in-service surveillance of the piping system. The surveillance requirements may include both the recording of life operating experience, and the periodic shutdown, reinspection, and testing of the system.

TASK 410 - DEFINE DESIGN ANALYSIS REQUIREMENTS The design rules developed under Task 312 will require that for the acceptability of a design, stresses will not exceed the limits developed. As an aid to the solution of recurring problems in the design of piping systems, analysis methods and procedures will be developed and formalized in the $4 x x$ series tasks.

The objectives of this task is to identify the specific analytical procedures to be developed in the $4 \mathrm{xx}$ tasks and the desired ranges of applicability. 
TASK 411 - ESTABLISH PROCEDURES FOR PRESSURE ANALYSIS Applicable analysis methods for determining pressure stresses in LMFBR Piping components will be compiled and evaluated, including consideration of generally available computer programs usable for pressure stress calculation.

Potential problems exist in the determination of pressure stresses in non-axisymmetric connections, such as T-joints, elbows, and laterals. Experimental data on stress indices and finite element computer programs appear to be most suitable for treating these non-symmetric components. Recommendations will be given, wherever possible, to using computer programs to generate curves of stresses or stress indices in parametric form where the problem boundary conditions can be specified definitively enough to prevent such formalization.

TASK 412 - ESTABLISH PROCEDURES FOR FLEXIBILITY ANALYSIS The objective of this task is to delineate the step-by-step procedures for piping flexibility analysis, and their relation to other stages in the design of piping systems. The degree to which creep and relaxation effects must be taken into account will be assessed, and procedures for treating these effects established.

Non-proprietary computer programs suitable for performing flexibility analyses will be identified in this task.

TASK 413 - ESTABLISH PROCEDURES FOR THERMAL STRESS ANALYSES Acceptable methods of determining thermal stresses in LMFBR Piping systems will be identified under this task. Particular emphasis will be placed on areas where the service requirements are more severe for sodium systems as contrasted with more conventional power piping systems, such as the large temperature range covered from cold to operating conditions, the severity of thermal coolant transients resulting from high coolant thermal conductivity and large T's, surface temperature fluctuations downstream of mixing tee, and localized thermal hot spots due to heating methods, etc.

Applicable analysis methods for determining both temperature and stress distributions will be compiled and evaluated, including consideration of generally available computer programs usable for thermal stress calculation. Solutions to many of the thermal stress problems are amenable to presentation in curve or chart form. 


\section{TASK 412 - ESTABLISH PROCEDURES FOR FLEXIBILITY ANALYSIS Continued}

Potential problems exist in the determination of thermal stresses in non-axisymmetric connections such as $\mathrm{T}$-joints and laterals. Finite element computer programs appear to be the most suitable for treating these non-symmetric components. These type programs will be included in the evaluation of applicable computer codes. Recommendations will be given wherever possible to using the computer programs to generate curves of stresses or stress indices in parametric form where the problem boundary conditions can be specified definitively enough to permit such formalization.

TASK 414 - ESTABLISH PROCEDURES FOR MISCELLANEOUS MECHANICAL LOADS Acceptable methods for determining stresses due to miscellaneous mechanical loadings will be identified under this task. Examples of such loadings are those which may result from hanger sleeve, ring, or lug attachments.

Available analysis methods such as those contained in welding Research Council Bulletin No. 107 dated August 1965, "Local Stresses in Spherical and Cylindrical Shells Due to External Loading," and computer programs capable of treating asymmetric loadings will be evaluated and compiled. Consideration will be given wherever possible to generate parametric curves which can be used by the designer to determine local stresses due to external loads for standard configurations.

TASK 415 - ESTABLISH PROCEDURES FOR FATIGUE ANALYSIS For low-temperature (below the creep range), low-cycle fatigue, there is a fair degree of information and understanding. For high-temperature, low-cycle fatigue, however, the situation is quite different. The material behavior becomes much more complicated at elevated temperatures because of the occurrence of creep, relaxation, and other diffusion processes.

It has been shown that frequency has a strong effect on fatigue properties. This is the same thing as saying that the strain rate is important, and related to this, the hold time in the cycle is important, with fatigue life decreasing as hold time increases.

Plastic strain, and in this case cyclic plastic strain, can have an important bearing on the precipitation of intermetallic phases and the strengthening effects which take place in the metal structure. This strain age hardening, while developing additional strength, also causes a reduction of ductility in the material. Since ductility is of prime consideration for fatigue resistance, this hardening effect, while increasing creep strength, reduces fatigue capabilities. 
Another problem applicable over the whole temperature range, is cumulative fatigue damage, where cyclic strains of greatly different magnitudes are experienced, and in a varying and probably random order of application. The order of application, as well as the difference in magnitude, may have a significant effect on the overall fatigue life.

In this task, procedure for the recommended method of fatigue analysis will be developed. These procedures will be compatible with the failure theory selected in Task 211, where practical, design fatigue curves will be included.

TASK 416 - ESTABLISH PROCEDURES FOR MODEL TESTING Those model test methods identified in Task 234 which appear to be of value to piping system analysis will be summarized. Procedures similar to those in B31.7, Appendix E, will be developed for performing each selected method. Limitations of the methods and interpretation of results will be discussed.

TASK 417 - ESTABLISH PROCEDURES FOR DYNAMIC ANALYSIS The analytical methods identified in Task 237 will be described and developed as necessary for use by the designer or analyst. System responses are, in the usual case, determined using digital computer techniques. Non-proprietary computer codes and their limitations will be covered in guide. Emphasis will be placed on providing guidance to the designer in formulating the mathematical model of the real system. Typical of areas where guidance or procedures might be provided are on the number of masses into which the system should be lumped to obtain reasonably accurate response information, limits on the amount of structural damping which can be assumed to exist, and sectionalization of the system to keep the number of elements (masses and flexible members) down to reasonable quantities.

TASK 418 - ESTABLISH PROCEDURES FOR INSTABILITY ANALYSIS The analytical methods identified in Task 240 will be described and developed as necessary for use by the designer or analyst. This section should outline a step-by-step procedure, tied in with other stages of design of the piping system, if possible, to provide a design which will be structurally adequate without too many stages of iteration. Areas to be analyzed in detail and procedures to be used will be outlined. Formulas will be indicated and simplifying or necessary assumptions recommended. Where practical, design aids such as curves or tables will be developed, using computer programs to cover a wide range of physical dimensions. Guidelines will be established to reduce the likelihood of instability - eg, pipesupport spacing and flexibility recommendations to minimize primary compressive loads, and the desirability of avoiding high external pressure conditions. 


\section{TASK 418 - ESTABLISH PROCEDURES FOR INSTABILITY ANALYSIS Continued}

The onset of instability must be determined for the various categories of loading, such as normal operating conditions, emergency conditions, and fault conditions. These would be compared with the limits established in Task 312. For some conditions a limit analysis procedure might be applied, while for others a plastic and/or elastic instability analysis might be indicated, utilizing more accurately the true physical properties of the material. In either case, curves or other charts will be worked up to facilitate design and analysis whenever possible. Typical examples will be worked out to illustrate the different analysis methods.

TASK 419 - DEFINE ANALYSIS R\&D REQUIREMENTS The objective of this task is to identify the R\&D required to complete, supplement, or confirm the recommended analysis methods and their range of applicability. Basic information on the analysis R\&D requirements will be developed in the analysis procedures tasks.

Relevant work under other elements of the LMFBR program will be identified and recommendations as to how the basic program might be modified to meet the analysis $R \& D$ requirements will be made. 
TASK 510 - PREPARE DESIGN GUIDE SECTION I, INTRODUCTION A preliminary outline for section $I$ of the design guide is as follows.

\section{SECTION I INTRODUCTION}

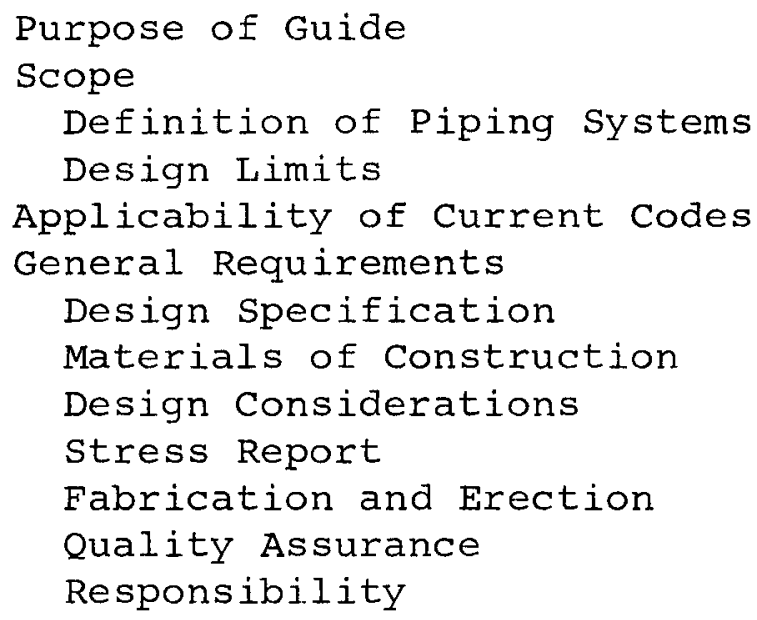

TASK 511 - PREPARE DESIGN GUIDE SECTION II, MATERIALS Section II of the design guide will include information on materials suitable for service in an LMFBR plant. A preliminary outline for this section is as follows.

\section{SECTION II MATERIALS}

Acceptable Materials Material Descriptions Limitations of Materials Deterioration of Materials in Service Manufacturing Processes Physical Test Requirements

Material Properties

Pertinent Design Stresses Physical Properties Fatigue Properties 
TASK 512 - PREPARE DESIGN GUIDE SECTION III, DESIGN This section will provide the basis for the piping design and layout for the plant. A preliminary outline for this section is as follows.

\title{
SECTION III DESIGN
}

\author{
Design Considerations \\ Environmental Effects \\ Pressure and Temperature \\ Penetration Reinforcing \\ Erosion and Corrosion \\ Thermal Expansion \\ Earthquake and Deadload \\ Dynamic Effects \\ System Interfaces \\ Preheating \\ Design Equations \\ Geometric Considerations \\ Design for Fabrication and Erection \\ Design for In-Service Surveillance \\ Standard Piping Components \\ Acceptable Piping Connection Geometries
}

TASK 513 - PREPARE DESIGN GUIDE SECTION IV, DESIGN ANALYSIS The purpose of the design analysis is to ensure that the piping system design prepared in accordance with section III of the Guide is safe. A preliminary outline for the section describing these analytical requirements is as follows.

\section{SECTION IV DESIGN ANALYSIS}

Definition of Analysis Requirements

Systems and Components

Loading Conditions

Basis for Analysis - Failure Theory

Categories of Stresses

Stress Limits

Limits for Categories of Stresses

Stress Computations

Methods of Combining stresses

Stress Summaries

Alternative Methods of Analysis

Specific procedures for computing stresses resulting from different types of loading conditions will be described in the Design Guide Appendix. 
TASK 514 - PREPARE DESIGN GUIDE SECTION V, FABRICATION, ERECTION, AND TESTING This section covers requirements for the construction of the piping system. A preliminary outline is as follows.

\section{SECTION V FABRICATION, ERECTION, AND TESTING}

Materials Testing Requirements

Mill Inspection and Certification

Repair of Defects

Construction Requirements

Welding Qualifications

Heat Treatment

Permissible Defects and Tolerances

Tolerances

Defect Sizes and Types

Inspection Requirements

Responsibility of Inspectors

Qualification of Inspectors

Summary of Inspectors Required

Inspection Procedures

Shop and Field Test Requirements

Material Tests

Component Tests

Assembly Tests

TASK 515 - SUBMIT DRAFT PRELIMINARY DESIGN GUIDE The draft of the first five sections of the Design Guide will be submitted to the AEC for review. Analytical procedures developed in Tasks 411 through 418 will be submitted with the draft of the Guide, and subsequently will become part of the Design Guide Appendix.

TASK 518 - SUBMIT R\&D REQUIREMENTS SUMMARY The R\&D requirements established in Tasks 312, 314, and 419 will be combined into a summary report and transmitted to the AEC for information and comment. This task will provide the basis for subsequently outlining the R\&D programs required for LMFBR piping systems.

TASK 610 - PREPARE COMPUTER ANALYSIS PROCEDURES Some of the analytical procedures developed in the $4 \mathrm{xx}$ tasks will require computer analysis. A review of non-proprietary computer programs will be made to identify those that can be of value. Where no suitable program is available, a discussion of the program requirements will be ' prepared. This will include a simple logic diagram, if applicable. 
TASK 611 - OUTLINE R\&D PROGRAMS REQUIRED FOR PIPING Using the R\&D requirements summarized in Task 518, outlines for the specific development programs to provide the required information will be prepared. The information developed in this task will be submitted to the AEC in the form of specific program recommendations and their relationships to the basic LMFBR program elements.

TASK 612 - TEST OF GUIDE METHODS Using typical LMFBR piping configurations furnished by AEC, the draft Piping Design Guide will be given a comprehensive test. Those analytical procedures that have been fully defined and documented will be tried out, and an attempt will be made to establish the 1 imitations of the methods used, as well as of the system configurations and/or components.

An important factor in the preparation of a competent analysis is the accuracy with which the design data are initially prepared and presented. The design guide test will serve as a useful vehicle for establishing guidelines for problem submission.

A model stress Report will be prepared at this time to establish acceptable presentation methods and formats. The example Stress Reports will be arranged for inclusion as an Appendix to the Design Guide.

TASK 613 - DESIGN GUIDE REVISION In the light of the experience gained in Task 612, appropriate revisions will be made to the methods incorporated in the guide. Where necessary, editorial changes will be made to clarify and amplify the test. Limitations established in Task 612 will be spelled out in all applicable sections of the guide.

TASK 614 - PREPARE DESIGN GUIDE APPENDIX, ANALYSIS, PROCEDURES, AND EXAMPLES An Appendix to the preliminary Design Guide will be prepared, and will include the following type of information.

ANALYSIS PROCEDURES Procedures that may be used for computing stresses will be provided for use by piping system designers in the design analysis.

EXAMPLE A design analysis will be provided as an example of the practical use of the design guide. The example will include one or more of the analytical tests made in Task 612 of configurations provided by the AEC.

COMPUTER ANALYSIS Flow diagrams of non-proprietary computer programs for analysis identified under this program will be included. References will be included to applicable non-proprietary programs. 
TASK 615 - SUBMIT PRELIMINARY DESIGN GUIDE AND R\&D RECOMMENDATIONS

The final submittal for Phase I will consist of the Preliminary Piping Design Guide and a separate report discussing requirements for R\&D to supplement the guide. 


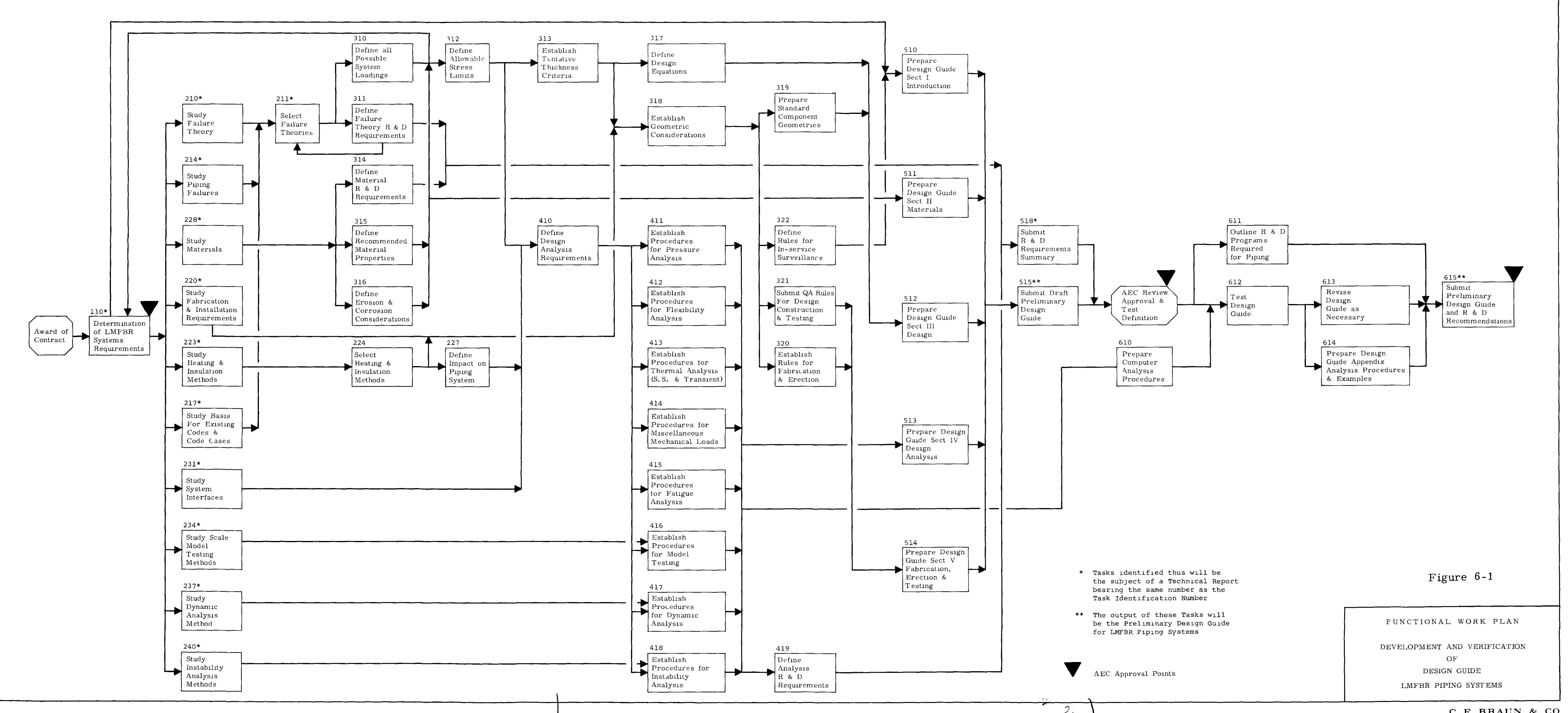


A description of Task 612, Test of Guide Methods, has been given on Page 6-26. At the present time the number and complexity of the systems to be provided by USAEC for this test of the Design Guide is unknown. It may be assumed that the systems will be prototypical of one or more LMFBR concepts under development, and might include the SPTF sodium loop even though the configuration of that system does not conform to normal LMFBR concepts.

Even before Task 612 gets underway, it will be necessary to check out the feasibility of the analytical procedures to be developed for the Design Guide, and for this purpose it is intended to prepare a sample primary loop configuration based on the concensus of 1000 Mwe follow-on studies, applying to it the most stringent set of conditions identified in Task 110, Establishment of LMFBR System Requirements.

Subsequent to the initial publication of the preliminary Design Guide, which marks completion of Phase I of the present contract, further Design Guide verification will be gained from the activities of Phases II and III. In order that the procedures of the Design Guide be given the broadest possible exposure, it is proposed that Braun and United Nuclear perform the design analyses independently, each reviewing the stress reports prepared by the other. In addition, LMEC will be invited to have sample designs checked by third parties having an interest in the applications of the Design Guide.

Provisional plans have been developed for Phases II and III, and these are described below.

PHASE II

The scope of Phase II consists of the design, analysis, and preparation of a construction package for representative piping systems selected by the AEC. Braun and United Nuclear will continue to work together as a team on this phase of work. Braun will take the prime responsibility, and will prepare designs, drawings, and specifications.

There are seven major tasks to be performed during Phase II. These are briefly described in the following paragraphs.

1) SYSTEMS CRITERIA For each system provided by the AEC for design and analysis, a system criteria will be developed. This criteria will be the basis for the work performed throughout Phase II. It will be the equivalent of the Design Specifications required in the ASME Code, section III, and the USASI Code, Section B3I.7. 
2) SYSTEMS DESIGN Each piping system will be designed in accordance with provisions in the design guide section II, Materials, and Section III, Design. The system will be laid out within the constraints given in the system criteria. Considerations will be given to the interfaces with other equipment, and supports will be designed to for expected static and dynamic loadings.

3) SPECIFICATION AND DRAWINGS A complete set of drawings and specifications will be prepared in sufficient detail to permit procurement of the system constructed in the field for a fixed cost. The level of detail will be typical of what is required for high quality piping systems for LMFBR power plants.

Detailed drawings of the system will include layout, spool drawings, welding and attachment details, supports and guides, and heating system details. The specifications will include materials, fabrication, erection, inspection, testing, plus insulation and heating system, if required.

4) DESIGN ANALYSIS An analysis and stress report for the system will be prepared in accordance with design guide Section IV, Design Analysis. The analysis may indicate areas where the design of the system is inadequate to meet service requirements, and may suggest design changes. Changes will be incorporated in the design where necessary and the new configuration analyzed to ensure compliance with the criteria.

5) CONSTRUCTION PACKAGE If desired by the AEC, the system design and specification will be incorporated into a package suitable for fixed-price bidaing by competent piping fabrication and erection contractors.

6) UPDATE GUIDE Throughout the design program, surveillance of work being performed on failure theory, materials, and other areas of study in Phase I will be continued. If useful, data developed by R\&D within the LMFBR program, or by organizations such as the code committees, will be incorporated into the guide. In addition, changes to improve clarity of the guide or procedures for analysis will be incorporated.

7) PHASE II FINAL SUBMITTAL The final submittal for Phase II will consist of a construction package, including drawings and specifications, plus the revised design guide. 
PHASE III

The final phase of the program is the construction and test operation of piping systems designed in Phase II. Construction and test operations will be performed by others. However, Braun will provide Title III services during construction and both Braun and United Nuclear will assist in defining the test program, monitoring it, and factoring the results into the final issue of the Design Guide.

There are five major tasks to be performed during Phase III. They are as follows.

1) TEST PROGRAM DEVELOPMENT A test program will be defined for the piping system or systems to be constructed. The specific objective of the tests will be established. For instance, the system may be intended for life testing, in which case it has no useful life left upon completion of the test program. Or it may be intended as part of an LMFBR Program test facility, in which case the test program will have to be compatible with the system's other uses. This test program development will include the preparation of a recommended instrumentation system for analyzing the effects of the tests.

2) QUALITY ASSURANCE During construction, a quality assurance program will be exercised on the fabrication, erection, and testing of the system. This program will ensure that each step of construction meets the requirements of the drawings and specifications prepared in accordance with the design guide.

3) TEST ASSISTANCE During the preoperational and operating tests, assistance will be given to the AEC and the test operators. The assistance may take the form of reviewing test operations and evaluating results.

4) UPDATE GUIDE The guide will be updated to reflect all new information developed in the test program, and in any other R\&D efforts performed within the LMFBR program.

5) PHASE III FINAL SUBMITTAL The final submittal for this phase of work consists of the updated design guide and a report summarizing and evaluating the test program. A summary will also be prepared outlining the status of any $R \& D$ still required for the guide. 
A review procedure has been established to help ensure that the work being done under this contract is consistent with other interdependent studies currently being performed under this and other Task Areas of the LMFBR Program Plan, as well as to provide a means of feedback on technological developments pertinent to Design Guide development.

Under the review procedure, the Liquid Metal Engineering Center (LMEC) is the coordinating agency. The preliminary drafts of Technical Reports prepared under this contract will be distributed by LMEC to appropriate Review Agencies designated by USAEC. Comments from Review Agencies will be evaluated by Braun to determine their validity. Valid comments will be incorporated into the Technical Reports, which will then be submitted in their final form to USAEC, San Francisco, for approval and release.

In addition to the review activity described above, LMEC will also participate in regularly-scheduled technical meetings and progress reviews between the principal participants of each task. LMEC will thereby be kept appraised of significant problems as they arise. In fulfillment of their liaison role in the LMFBR Program, LMEC will keep the participants informed of other developments within their purview which might have a bearing on the Design Guide tasks.

Contact will be maintained with Liquid Metals Information Center (LMIC) and Nuclear Safety Information Center (NSIC) to obtain pertinent information from time to time and to keep abreast with the latest literature. 
The Design Guide work plan contains provision for the summarization and submission of R\&D requirements identified during the course of development of the Guide. However, it is recognized that some R\&D may be necessary before even preliminary completion of the Design Guide can be achieved. Two categories of $R \& D$ are therefore visualized - (a) short-term R\&D considered necessary to accomplish initial completion of the Design Guide; and (b) long-term R\&D recommended to establish further confidence in, and backup support for, procedures developed during preparation of the Guide.

In view of the urgent nature of $R \& D$ in the short-term category, USAEC will be advised of their need as soon as they arise. R\&D requirements in the long-range category will also be communicated to USAEC before actual completion of Task 615 if a delay seems likely to jeopardize the goals of the LMFBR Program.

LMEC will keep participants in this project informed of R\&D programs already underway, or planned for early commencement, which might have a bearing on this activity. The work of the subgroup on Elevated Temperature Design will be followed with interest, as will be the developments following upon the recommendations of the Pressure Vessel Research Committee (PVRC), as reported in the bimonthly reports of ORNL Nuclear Safety Research and Development Program. 


\section{ORGANIZATION AND SCHEDULE}

The project organization chart is given in Figure 10-1.

The tentative critical path schedule for the project is shown in Drawing 4122-100-KE-1 on Page 10-3. It will be noted that a fourweek period is allowed for the review of Technical Reports by outside agencies (see section 8). Achievement of the schedule objectives is strongly dependent upon receipt of review comments within the allotted time. 
PROJECT ORGANIZATION

DEVELOPMENT AND VERIFICATION OF DESIGN GUIDE

FOR LMFBR PIPING SYSTEMS

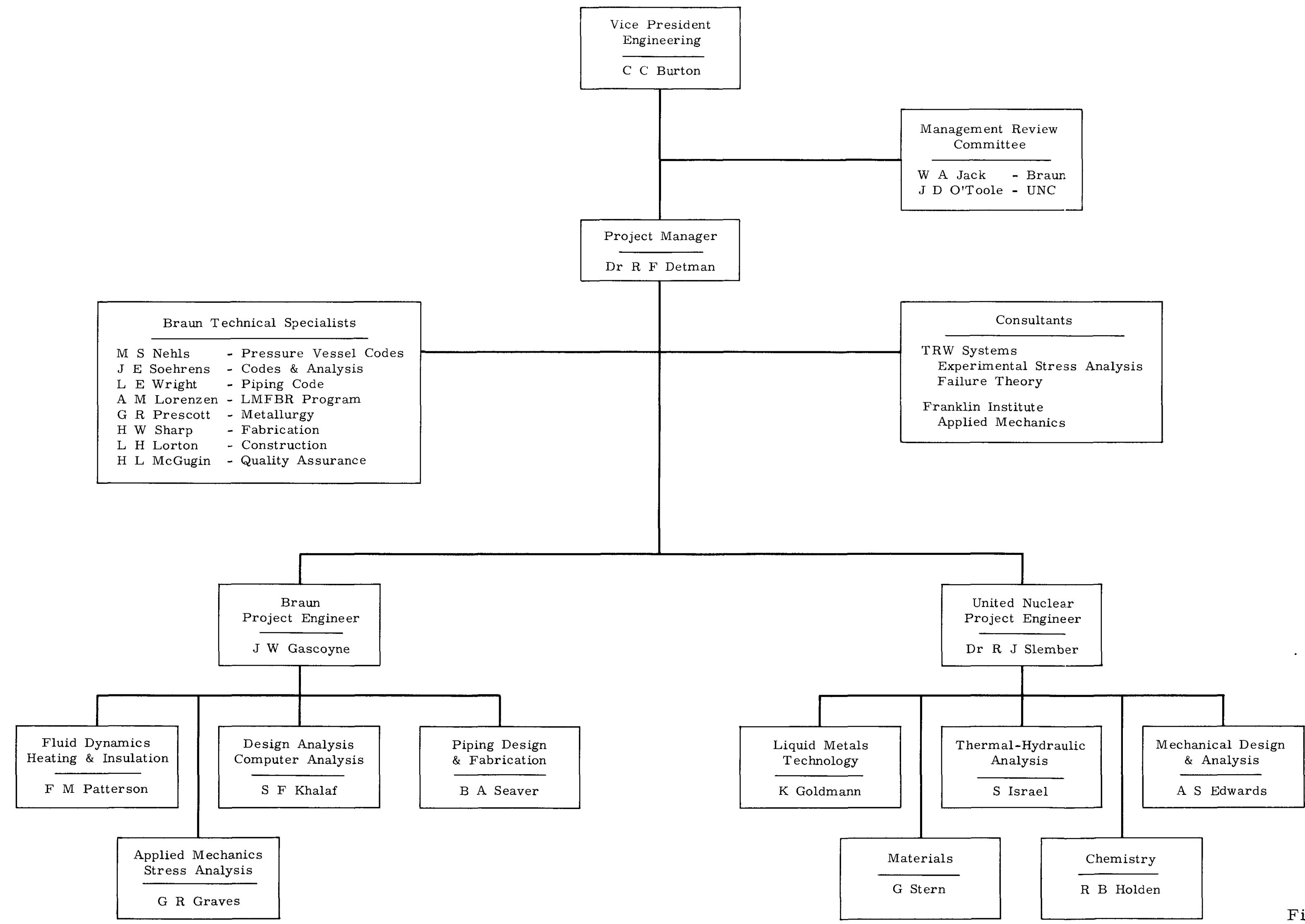

Figure 10-1 


\section{BIBLIOGRAPHY}

1 Liquid Metal Fast Breeder Reactor Program Plan, LMFBR Program office, Argonne National Laboratory. AEC R\&D Report, Reactor Technology, WASH-1101, Volume 1, Overall Plan, August 1968, and WASH-1103, Volume 3, Components, August 1968.

2 Summary Description of 1000 Mwe LMFBR, General Electric Company, Advanced Products Operation, Sunnyvale, California, November 6, 1968. Presented at International Conference on Sodium Technology and Large Fast Reactor Design, ANL, November 1968.

31000 Mwe LMFBR Follow-on Study-Summary Description of Reference Concept, Atomics International, Division of North American Rockwell Corporation, Canoga Park, California, November 1968. Presented at International Conference on Sodium Technology and Large Fast Reactor Design, ANL, November 1968. 


\section{WORK PLAN REVISION}

BASIS FOR CHANGE The development of the Design Guide was directed to begin with the best proven technology, extrapolating as necessary, and considering all other developments. The work plan was thus formulated to follow a logical sequence of tasks beginning with studies of the best proven technology. It became apparent during these studies that proven technology does not exist for the conditions envisioned for LMFBR piping and that extrapolation of existing technology from less severe conditions would introduce large uncertainties resulting from the unknown behavior of materials exposed for long periods under LMFBR operating conditions. This development brought about the following changes in the work plan.

FAILURE THEORY The failure theory studies indicated that no single theory of material behavior was ideally suited for analysis of all the various stress-strain situations that must be investigated. Consequently the selection of a failure theory or theories as a basis for design was deleted in favor of a more expedient approach to permit the work to proceed. The approach taken was to select a set of interim design bases which could be used immediately for development of design analysis procedures. The verification of the suitability of these interim design bases was deferred for later studies which would provide recommendations for R\&D to fill the need for information on material behavior.

TASK REVISIONS The previously defined Task 210 was unchanged and the results of the study were issued in Technical Report 210, A study of Failure Theories as Related to LMFBR Piping systems. The previously defined Task 211, Selection of Failure Theory, was retitled Selection of Interim Design Bases. No technical report on Task 211 was issued, but a task memorandum was written summarizing the Interim Design Bases and these were then incorporated in the final issue of Technical Report 217, A Review of Piping and Pressure Vessel Code Design Criteria.

CRITICAL PATH REVISION The technical problems associated with failure theory studies and selection of interim design bases consumed more schedule time than the original critical path schedule permitted. To overcome the delay in starting on analysis procedures, the time period for 300 and 400 series tasks was compressed. This resulted in a peak manhour loading during the two months following completion of Task 211, Selection of Interim Design Bases. The critical path during this period follows three parallel paths ending with completion of analysis procedures. The original completion date for the preliminary draft of the Design Guide was retained by the allocation of additional manpower during the preparation of analysis procedures. The revised critical path schedule is shown in Revision 3 of Drawing 4122-100-KE-1 on Page 12-3. 


\section{BASIS FOR CHANGE Continued}

TECHNICAL COORDINATION Another incidental change made to the Critical Path Schedule is the relocation of tasks performed by others, shown as Outside Agency Review of Technical Reports. These tasks, with the exception of review of the design guide itself, have been set off the critical path and out of the task sequence. The reason for the change is the unpredictable period of response from outside reviewers. The responses received during the first six months of the project varied from the scheduled four weeks to several months.

ADDENDUM The studies of failure theory and selection of interim design bases led to the conclusion that an explanation of the reasons for selection of design bases would be helpful to reviewers in evaluating the design guide. Consequently a proposal was made to prepare an addendum to the Design Guide which would present the philosophy employed in its development. This additional work is shown on the critical path schedule as Task 500, Addendum on Design Philosophy. 


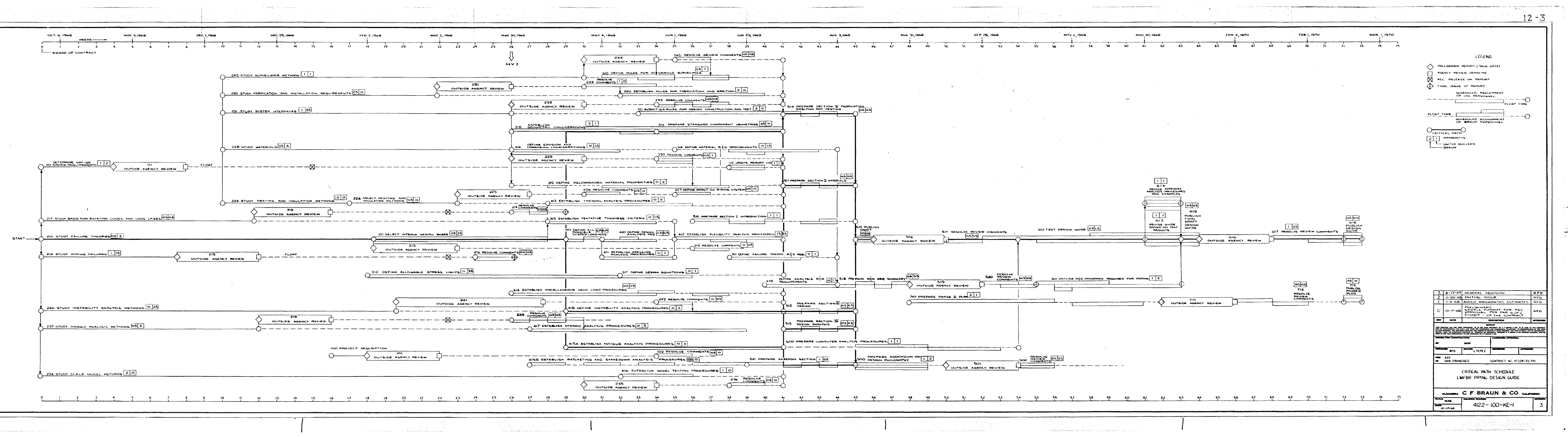




\section{APPENDIX A}

\section{LMFBR PROGRAM PLAN (I) \\ VOLUME 3, COMPONENTS - TASK AREA 3-8}

Task 3-8.1 Development of Program Implementation Plan

Objective

The objective of this task is to develop a detailed plan for implementing the development program for piping analyses and fabrication.

\section{Scope}

The scope of this task covers a survey and evaluation of the existing state of the art and related on-going development programs for piping-system design, analyses, fabrication, and installation. Included is the technology applicable to all industrial piping, i.e., chemical, power (nuclear and fossilefueled), gas, etc. Information obtained will be used as the basis for preparation of the detailed plan for implementation.

\section{Background Information}

Surveys have been made of piping failures within the power industry; fracture mechanics is in the state of development; thermal-stress fatigue as related to high-temperature piping flexibility is under investigation; local stresses due to external loadings on cylindrical shells have been studied; and theoretical elastic analysis for fittings is under development. However, much of the information being developed concerns design of piping for water systems. Cognizance of the present state of the art is required to avoid duplication of effort and to guide the verification of analyses as applied to LMFBR systems.

\section{Plan of Action}

Tasks 3-8.2 through 3-8.4 provide for the development (or establishment) of a technology for the design and fabrication of LMFBR piping systems. However, the interrelationship among these tasks must be properly specified, phased, and guided.

Several organizations, knowledgable in piping design and fabrication-including appropriate code requirements and current endeavors to improve these requirements--will review the Program and prepare a detailed plan of implementation.

The present piping technology and ongoing programs wi11 be thoroughly reviewed and evaluated. The activities, based on LMFBR piping requirements established under Task Area 3-1, will include: 
(1) Existing analytical procedures, including computer programs, related to piping-system designs will be surveyed. Applicability to LMFBR sys tems will be ascertained, limitations identified, and areas of design and operation requiring new analytical concepts delineated.

(2) Availability and reliability of existing data on physical and mechanical properties for the structural materials of interest will be reviewed. Similarly, applicability of existing design values, such as fitting flexibility and stressintensification factors, will be determined. Inadequacies will be defined and additional data needs and development identified.

(3) Existing piping systems, nuclear or otherwise, will be surveyed to collect, analyze, and classify data on failure incidents to assess mechanisms causing failures and determine specific areas of technology requiring further development.

(4) Prior development programs on piping systems will be evaluated to guide detailed planning. Consideration will be given to such features as use of reduced vs full-scale tests for experimental verification of analytical methods and procedures, test instrumentation required, number and type of tests needed, length of test time, and test procedures.

(5) Industrial fabricators will be canvassed to assess product variations expected, due to different fabrication processes and levels of quality-assurance management. How these variations affect applicability and reliability of analytical predictions of performance will be assessed.

All of the above efforts will be reported to substantiate the piping development implementation plan, which will include as a minimum:

(1) A description of the work to be performed, expanding in detail the scope and activities of the succeeding tasks of this task area

(2) A detailed description of how the work is to proceed--analytical method development, experimental verification, number and types of tests needed, test facilities, etc.

(3) Technical basis for the above work with specific notation of how the developed technology is to be used

(4) Interface relationships with other development programs, either indus trial or AEC sponsored including those called for in the Plan--e.g., development of elasto-plastic and fracture mechanics analytical design methods under 
Task 3-8.1

Sub-Task 3-9.1.2 of the task area on Reactor Vessels and Related Components.

Under this Priority I task, work will begin in FY 1969 and is scheduled for completion in six months, at an estimated cost of $\$ 100,000-\$ 200,000$. 
Task $3-8.2$

Task 3-8.2 Development of Design Technology for Piping

Objective

The objective of this task is to develop a design guide describing, in detail, methods of analyses to predict behavior of piping systems.

\section{Scope}

This task covers the methods of analyses for piping systems subjected to the following types of loadings:

(1) Dead loads, including the weight of the pipe, fluid contents (varied between $0-100 \%$ ), appendages (i.e., heaters, insulation, instrumentation, thermal shields), etc.

(2) Loads due to thermal effects, including thermal expansion of the piping system, temperature transients, circumferential gradients resulting from stratification at low flow, differential themal expansion at joints of dissimilar materials, and localized temperature gradients due to internal heat generation (nuclear) and heat flow

(3) Pressure and other loads, including forces due to both internal and external pressure, structural discontinuities, out-of-roundness, fit-up alignments, etc.

Also included in this task is the theoretical development of methods of analyses for dynamic behavior of piping systems. These analyses will cover the effects of live loads, such as: fluid dynamic forces (velocity, pressure drop, startup and shutdown pressure surges, etc.), hydraulic hammer, seismic disturbances, and vibration as a function of forcing frequencies and inherent sys tem damping.

\section{Background Information}

The Code for Pressure Piping, ASA B31.1-1955, considers gross thermal expansion and, in a sense, thermal fatigue, since the stress-reduction factor becomes less than one for more than 7000 cycles. However, thermal loads that produce creep, high- and low-cyclic fatigue, cyclic creep, localized high strains, etc., are not covered now.

The static loads imposed on large diameter, trin-wall systems, operating at high temperatures, may require elasto-plastic rEthods of analyses. Supports, guides, and anchors tend to concentrate the loads, and such areas will require 
special attention. Buckling stability of straight lengths of pipe and wrinklings of fittings also must be considered. In addition, thermal ratcheting because of system pressure changes, which are uncommon in ordinary piping systems, may be important in LMFBR plants.

Analysis of piping flexibility based on elastic theory is well developed; most companies within the industry have computer codes for rapid solution of complex configurations. However, to confidently quantify the analysis for LMFBR systemis, the stress-range concept and the existing values of flexibility and stress-intensification factors need to be reviewed. These factors may be affected by the fact that large-diameter, thin-wall fittings probably will have different geometrical tolerances than those specified now for code fittings and that they may be either smooth or mitered.

\section{Plan of Action}

The plan for implementation developed under the preceding task will define the analyses to be pursued and the coordination of the activities of this task and Tasks 3-8.3 and 3-8.4. The general approach, however, will be a parallel effort of analytical development with physical testing of prototypal components and systems for verification.

Under this Priority 1 task, work will begin in FY 1969 and is scheduled for completion in FY 1975, at an estimated cost of $\$ 2.0$ million-\$2.5 miliion.

Sub-Task 3-8.2.1 Analytical Techniques for Static Conditions: The range of pipe sizes, materials, wall thickness, and operating conditions of interest for the Plant Design element, will be compiled under Task Area 3-1. Data on material properties required for the analyses will be developed under the Fuels and Materials and Sodium Technology elements in response to Task Area 3-3. The activities of this sub-task will use current data on materials properties and extrapolate where necessary. As more detailed and reliable data become available under the other elements of the Program, the analyses will be modified where applicable.

Behavior of two- and three-dimensional piping systems and the major fittings (90 elbows, $180^{\circ}$ returns, tees, and laterals) will be predicted analytically for thermal loads that may be imposed by plant operating conditions. Elastic 
and elasto-plastic methods of analysis, including creep, stress-to-rupture and fatigue, will be used where applicable. Effects of geometric discontinuities and piping tolerances, i.e., out-of-roundness, wall thickness, bend radius, inside and outside diameter, etc., will be determined. Similarly, the analyses will reflect the methods and limitations of fabrication--e.g., bend radii, formed and mitered $\mathrm{ell} s \mathrm{~s}$ and returns, reinforced and non-reinforced fabrication tees and laterals, etc.

Prototypes of the above fittings with welded pipe ends, fabricated under Sub-Task 3-8.4.1, will be mechanically tested to determine the adequacy of the above analyses. Tests will be conducted at normal LMFBR temperature conditions and simulated load conditions (cyclic bending and torsional). Data required, as specified by the analysts, will be obtained from a test program performed in accord with the detailed implementation plan of Task 3-8.1. The number of fittings to be tested and overlaps in size ranges to provide most information with fewest tests will be planned statistically. Measurements of: maximum stress and location; local yielding; flexibility and stress-intensification factors; and stability will be included.

Differences between the results of experimental measurements and analytical prediction of behavior will be evaluated. Reasons for any disagreement will be determined and required modifications of the analysis or the test will be made.

Progress reports, incident documentation, and data reduction will be prepared and test-evaluation results will be published. In addition, analytical procedures will be described in detail. Standard worksheet formats will be established for hand calculations, and, where a computer code is used, a code report will be prepared, including a description of code limitations, assumptions, required input data, and output that can be obtained.

Sub-Task 3-8.2.2 Analytical Techniques for Dynamic Conditions: To complete the piping analyses, techniques for predicting the behavior of a typical LMFBR piping system under dynamic conditions will be developed. A design analysis of the reference system (the test loop designed as part of Task 3-8.3) will be made to predict the effects of typical LMFBR dynamic loads, including: limiting sodium velocities; startup and shutdown pressure surges; pressure drop; and hydraulic hammer as a function of valve-closure time. Amplitude and frequency of vibration due to the above will be predicted. Damping effects of system restraints-- 


\section{Task 3-8.2}

such as supports, anchors, guides, and external loadings of insulation or shieldingwill be considered in the analysis.

Analytical procedures will be verified, using water as the flowing medium, in a test loop to be erected at the LMEC. The loop will be designed and fabricated under Task 3-8.3. Valves developed in Task 3-8.5 may be tested hydraulically in the loop; these will be used to simulate hydraulic hammer.

In addition to the above analyses applicable to the entire system, analytical techniques will be developed to predict performance of those specific areas of the system, such as temperature mixers (mixing tees), for which present methods are not adequate. The analysis will permit determination of specific operating conditions (flow and temperature of the mixing streams) which could lead to temperature and stress distributions that might result in thermal fatigue. This analysis will be verified by operation of mixing tees in sodium under a simulated plant operating environment in a facility such as the Sodium Pump Test Facility (SPTF) at the LMEC.

The analysts will prepare the test program needed for verification of their theoretical results. Included will be the test conditions, range, and sequencing of controlled variations in operating parameters, and the test data required. LMEC, in conjunction with the analysts, will prepare the detailed test procedures for test performance in accord with the specified program. The tests will be conducted by LMEC.

The analysts will evaluate test results to determine the validity of the analytical methods. Discrepancies between actual and predicted performance will be resolved either by modification of the analytical techniques or additional testing. The analytical models developed to predict the behavior of a large-. diameter piping system under dynamic conditions will be described in detail. Methods for performing the analysis will be presented. Work sheet formats for hand calculations will be prepared and, where a computer code is used, a code report wi 11 be provided.

Sub-Task 3-8.2.3 Design Manual: The above analytical procedures and the technology developed in Tasks $3-8.3$ and $3-8.4$ will be assembled into a pipingdesign manual for LMFBR systems. The manual will consist of a detailed description of methods of analyses and how they are to be used. A schedule of appropriate stress indices for fittings will also be included (if required). Sample 
Task $3-8.2$

specifications for the design, fabrication, and erection of fittings and systems (including inspection, testing, and cleanup) will be prepared. The specifications will show applicable sections of existing codes and standards and the supplemental analytical techniques and fabrication details, developed under this task area, required for design of $L M F B R$ piping systems.

LMEC will verify the applicability of the manual by using the techniques and procedures in it to perform a complete analysis of the SPTF. These calculations then will be compared with performance data obtained during facility operation. Since the facility is to be designed using current technology, the above evaluation will permit a reasonable determination of the value of the technology development. 
Task 3-8.4

Task 3-8.4 Development of Fabrication Technology

The development of standards and specifications within this task covers the shop fabrication of pipe and fittings and the field erection of these parts into a coolant transport system. General objectives, background, and plan of action are described under 3-C, Activities for Development of Fabrication Technology, in the Introduction. The activities will be closely coordinated with the development of the preceding tasks.

The geometry (radius of curvature); tolerances for wall thickness, diameter, and ovality; surface finishes; and structural discontinuities of fittings (mitered and smooth), all can affect the validity of analyses. The procedures used for fabricating pipe and fittings must, therefore, produce components that can be analyzed. Furthermore, proper procedures can minimize the detrimental effects of stress raisers and the increase in stiffness (due to excessive ovality poorly oriented with respect to the imposed loads).

Experience with welding large-diameter (12 in. and larger) stainlesssteel pipe has shown that excessive distortion can result. The draw down of a circumferential weld can be as much as $\frac{1}{4} \mathrm{in}$. on a $12 \mathrm{in}$. diam pipe. Welding procedures must be established to minimize excessive distortion. The aerospace industry faced similar problems which were solved by development of special end preparation in conjunction with welding procedures. It is believed that a similar development may be required for LMFBR systems.

After fabrication, procedures are needed to maintain acceptable tolerances. These tolerances must be maintained during transit, fit-up, and erection. Special fixtures may be needed; they will be developed in this task.

Under this Priority 1 task, work is scheduled to start in FY 1969 and conclude in FY 1971, at an estimated cost of $\$ 400,000-\$ 600,000$.

Sub-Task 3-8.4.1 Fabrication Techniques for Pipe and Fittings: Designs for large pipes and fittings that have been used for hydraulic and gas systems will be surveyed. Conditions of operation, statistical performance, and economic data will be compiled. The advantages and disadvantages of each design type and fabrication process will be evaluated in terms of LMFBR sys tem requirements. Aspects of the types and processes judged most promising will be described. Similarly, potential applicability of process-fabrication for fabricating 
large fittings and pipe will be assessed. Examples of the processes are: machine and hand welding (process parameters, end preparation, fit-up, and fixtures); forming processes (including hot bending, forging, and extrusion); and inspection procedures, both as to type and time of the process (such as the need for rootpass radiography and dye-penetrant inspection). Merits of each process will be described and reported, and those appearing to have the most merit will be identified.

From the above surveys and evaluations, specifications reflecting the design requirements of 7 asks $3-8.2$ and 3-8.3 will be prepared for procuring lengths of pipe, $90^{\circ}$ and $180^{\circ}$ fittings, tees, and laterals. These specifications also will refer, to the maximum extent applicable, to the standards of Task 3-2.2 and will include the provisions for quality and reliability assurance of Tasks 3-2.3 and 3-2.4.

Samples procured from at least three suppliers will be subjected to both non-destructive and destructive testing to determine conformity to specifications (soundness of material, out-of-roundness, consistency of bend radii, uniform wall thickness, surface finish, geometric discontinuities, etc.). The results of the examinations will be evaluated as to how the tolerance limits affect the structural integrity of an LMFBR system. If the specifications have permitted unacceptable material analyses or dimensional tolerances, the specifications will be upgraded and methods for product improvement recommended.

Final processes will be demonstrated by fabrication of enough selected fittings to establish the distribution of part-to-part variations of significant parameters. These fittings will be used under Sub-Task 3-8.2.1 to verify the analytical procedures for predicting performance.

Sub-Task 3-8.4.2 Field Installation Procedures: Field-erection processes will be developed for resolution of typical problem areas such as those associated with closure weldments and cold springing.

As other significant problem areas are identified in development of the design technology, they will be resolved. The developed specifications and procedures will be verified during erection, at the LIIEC, of the pipe loop to be designed and fabricated under Sub-Task 3-8.3.2.

Two types of weldments need to be considered: joining techniques, where access to both sides of the weld area is available; and closure methods, where 
Task $3-8,4$

welding is limited to only one side. Based on an industrial survey, existing practices and the need for development of new procedures will be evaluated and tentative process specifications for LMFBR systems will be prepared. Methods to control distortion of the relatively thin sections and quality control and acceptance testing will be examined. Features such as in-place welding methods-including means for shrouding with inert gas (system flooding or pipe dams)-will be developed. Critical process parameters, weld-end preparation and clean $1 i$ ness, fit-up, fixture-support and restraint, chill blocks, etc., will be included in the final process specifications and procedures.

The piping code (ASA B31.1) does not allow a reduction in stress for cold springing; however, a reduction in end reactions is allowable and many powerpiping systems are cold sprung. The usual practice is to cold spring at a region of the piping system where the bending stresses are low. The pipe is cut short and mechanically jacked into place without attempting to provide for pre-strain compensation of bending stresses. If cold springing is considered for LMFBR systems, methods of applying mechanical loads must have special attention. Improperly applied cold spring loads can plastically strain the large diameter, thin-wall pipe. Since LMFBR piping systems have heaters, it may be feasible to heat the pipe to close the cold-spring gap instead of closing it mechanicalty. 